\title{
Grain size and alloying effects on dynamic recovery in nanocrystalline metals
}

\author{
Z. Sun ${ }^{\mathrm{a}, \mathrm{b}}$, S. Van Petegem ${ }^{\mathrm{a}}$, A. Cervellino ${ }^{\mathrm{c}}$, W. Blum ${ }^{\mathrm{d}}$, H. Van Swygenhoven ${ }^{\mathrm{a}, \mathrm{b},{ }^{*}}$ \\ ${ }^{\text {a }}$ Photons for Engineering and Manufacturing, SYN, Paul Scherrer Institut, CH-5232 \\ Villigen-PSI, Switzerland \\ b NXMM laboratory, IMX, École Polytechnique Fédérale de Lausanne, CH-1015 Lausanne, \\ Switzerland \\ ${ }^{\mathrm{c}}$ Material Sciences, SYN, Paul Scherrer Institut, CH-5232 Villigen-PSI, Switzerland \\ ${ }^{\mathrm{d}}$ Department of Materials Science and Engineering, University Erlangen-Nürnberg, D-91058 \\ Erlangen, Germany \\ * helena.vanswygenhoven@psi.ch
}

\begin{abstract}
Dynamic recovery in nanocrystalline $\mathrm{Ni}$ and $\mathrm{Ni}_{50} \mathrm{Fe}_{50}$ with respective grain sizes of $65 \mathrm{~nm}$ and $15 \mathrm{~nm}$ is studied using stress reduction tests during in situ X-ray diffraction. The results are compared with a previous study on NC Ni with $35 \mathrm{~nm}$ grain size. Defect recovery by means of grain boundary processes plays an important role in controlling the strength evolution resulting in a constant flow stress during uniaxial deformation. The relative contributions of dislocation and grain boundary accommodation mechanisms are discussed in terms of grain size and alloying.
\end{abstract}

Keywords: nanocrystalline metals, stress reduction, in situ X-ray diffraction, dynamic recovery

\section{Introduction}

Transient testing has proven to be a suitable tool to obtain information on rate limiting deformation mechanisms [1]. The basic principle behind such tests is to suddenly change the 
imposed deformation conditions during a monotonic test and evaluate the subsequent response of the material to these new conditions [1]. Here one assumes that the microstructure remains constant during the transient so that one is solely probing the effect of the rate sensitivity of the deformation mechanisms. There are two main philosophies in transient testing: one is to conduct sudden changes in the strain rate, usually called strain rate jump tests [2][3][4], the other is to control the stress and conduct sudden changes in the applied stress, followed by a measurement of the stress relaxation [2][5][6][7][8] or the strain at constant stress [9][10][11].

Generally, strain rate jump tests need large magnitudes of plastic and anelastic strains to reach the new level of flow stress such that the condition of constant structure may be violated. In contrast, stress change tests can be performed relatively fast, as, in principle, only changes of elastic strain are required. In other words, the assumption of constant microstructure is easier to fulfil when transient is controlled by stress at very short times. Traditionally, stress change tests at constant temperature are focusing on three major goals: (1) determination of the activation volume of the dominant deformation mechanism by examining the relation between plastic strain rate and stress during the transient; (2) decomposition of the macroscopic stress into an effective (thermal) stress $\sigma^{*}$ and an internal (athermal) stress $\sigma_{i} ;$ (3) identifying those deformation mechanisms that may play a minor role in the determination of the high value of the flow stress but might be essential to the development of a constant deformation resistance.

The study of dynamic recovery processes via a long-term stress reduction is based on the concept of the third goal. By performing a large stress drop, the thermally activated dislocation glide is suppressed enough so that dynamic recovery of defects can be brought into foreground and captured during the subsequent transient period. This technique has been early applied on single crystals [12][13] and coarse grained polycrystals [14][15][16][17] that 
after prior deformation contained subgrains with (mainly) low angle boundaries. These works reveal that it is low angle boundaries that control the dynamic recovery and strength evolution during plastic deformation.

Recently, stress reduction tests were performed on nanocrystalline (NC) Ni with an average grain size of $35 \mathrm{~nm}$, a material that contains mainly high angle grain boundaries [18]. In addition, these tests were combined with in situ X-ray diffraction, which allows better understanding of the mechanical response of the material during transients. In particular, it was found that at least two competing deformation mechanisms exist that have opposite effect on the diffraction peak broadening: dislocation-based and grain boundary (GB) accommodation mechanisms. It was further demonstrated that the latter are of importance to dynamic recovery in NC metals, which controls the strength evolution while producing the plastic strain. It is concluded that the observation of constant deformation resistance during uniaxial deformation of $\mathrm{NC}$ metals originates from a dynamic equilibrium between defects generation and recovery.

In present work we explore the effect of grain size as well as alloying on the GB-mediated recovery mechanisms in NC metals. In situ stress reduction experiments are performed on $\mathrm{NC} \mathrm{Ni}$ and $\mathrm{Ni}_{50} \mathrm{Fe}_{50}$ with respective grain sizes of 65 and $15 \mathrm{~nm}$. The results are compared with those previously obtained for the NC Ni with $35 \mathrm{~nm}$ grain size.

\section{Experimental}

Two batches of NC Ni were synthesized by pulsed electro-deposition (PED) at the University of Erlangen-Nürnberg. Table 1 provides the deposition parameters. The main difference between the two batches is the saccharin content added for grain refinement. $\mathrm{NC} \mathrm{Ni}_{50} \mathrm{Fe}_{50}$ was purchased in sheet form from Integran Technologies. Details on the initial microstructure for all three batches were obtained by X-ray powder diffraction at the Swiss Light Source 
(SLS). Table 2 compares the average grain size, the root-mean-square (RMS) strain, and the ratio of integral intensities of the $\{111\} /\{200\}$ diffraction peaks. The latter provides a measure for the texture. We find that the intensity ratios are lower than that of a randomly textured f.c.c. metal $(\sim 2)$, in agreement with the expected (100) out-of-plane texture. The number-averaged grain size as well as the RMS strain was determined by a conventional Williamson-Hall analysis on the $\{111\}$-grain family. The NC Ni batches have average grain sizes of $35 \mathrm{~nm}(\mathrm{NC} \mathrm{Ni} 335)$ and $65 \mathrm{~nm}(\mathrm{NC} \mathrm{Ni} 65)$ and a similar RMS strain of $\sim 0.3 \%$. NC $\mathrm{Ni}_{50} \mathrm{Fe}_{50}$ exhibits a rather small grain size of $15 \mathrm{~nm}$ and high RMS strain of $0.5 \%$. A more indepth characterisation for $\mathrm{NC} \mathrm{Ni}_{50} \mathrm{Fe}_{50}$ and $\mathrm{Ni} 35$ can be found in Refs. [19] and [18], respectively.

\section{Table 1}

Table 2

All mechanical tests were performed with a miniaturized tensile machine (MTM), in which $3 \mathrm{~mm}$ mini dogbone-shaped specimens with a nominal cross-section of $200 \times 200 \mathrm{um}^{2}$ were used. The specimens were machined by wire electro-discharge machining (EDM) and then electro-chemically polished to remove the resulting recast-layer [20]. For in situ mechanical testing during X-ray diffraction, the MTM machine was mounted at the powder diffraction station of the Materials Science Beam line at the SLS. During deformation diffraction patterns were continuously recorded by a one-dimensional microstrip detector (MYTHEN [21]) with a frequency of $0.1 \mathrm{~Hz}$. The diffraction peaks were fitted by a split Pearson VII function, yielding information on peak broadening (in terms of the full-width at halfmaximum - FWHM), peak position, peak intensity, and peak asymmetry.

For small-grained materials, the peak broadening is a convolution of multiple contributions. The most important ones are: (1) the coherent scattering length which is related to the grain 
size, twin density, and stacking fault density, and (2) elastic strain variations that are either caused intragranularly by defects (for instance dislocations) in the grain interior or intergranularly by inhomogeneous strains among the grains. During an in situ continuous loading, the evolution of peak broadening is a net balance between multiple contributions. On the one hand, the peak width is expected to increase when defects (such as dislocations, twins etc.) are involved or when different grains experience an increasing different average stress. On the other hand, GB accommodation processes play an important role in the recovery of defects and internal stresses, which leads to a reduction of the diffraction peak width [18][22]. In addition, a decline of peak width may also be ascribed to an increase in coherent scattering length when deformation mechanisms such as grain coarsening or detwinning are triggered during loading [23][24][25][26][27][28].

\section{Results}

\subsection{Continuous tensile tests at constant strain rate}

A series of continuous tensile tests with constant strain rate ranging from $10^{-6} / \mathrm{s}$ to $10^{-3} / \mathrm{s}$ were conducted on the $\mathrm{NC} \mathrm{Ni}$ batches. Under these conditions, the stress-strain curve evidences first a pronounced strain hardening before reaching a constant flow stress. The constant flow stress can be considered as a quasi-stationary state where there is a dynamic equilibrium between different deformation mechanisms. Figure 1 presents these quasistationary stress values for NC Ni_65 (orange circles) and compares them with the values obtained for NC Ni_35 (pink triangles) [18]. For all strain rates, the material with the larger average grain size has lower values for the flow stress, suggesting a Hall-Petch strengthening. For both NC Ni batches the quasi-stationary stress values increase with increasing strain rate. However, this is not the case for $\mathrm{NC} \mathrm{Ni}_{50} \mathrm{Fe}_{50}$ : the flow stress, denoted as the blue squares in Figure 1 , is hardly dependent on the strain rate within the range $6 \times 10^{-7}$ to $10^{-3} / \mathrm{s}$, in 
agreement with the former findings in Ref. [20]. In the supplementary information, the flow curves for the highest $10^{-3} / \mathrm{s}$ and the lowest $6 \times 10^{-7} / \mathrm{s}$ strain rate are displayed for NC Ni and $\mathrm{NC} \mathrm{Ni}{ }_{50} \mathrm{Fe}_{50}$.

Figure 1

Figure 1 The quasi-stationary stress values for NC Ni_35 (pink triangles), NC Ni_65 (orange circles), and $\mathrm{NC} \mathrm{Ni}_{50} \mathrm{Fe}_{50}$ (blue squares) obtained from continuous tensile tests at constant strain rates.

\subsection{Conventional stress reduction tests}

On all three batches a series of in situ stress reduction tests were performed. Figure 2 displays a schematic of the principle. Each specimen is first strained to a pre-defined stress $\sigma_{0}$ at a constant loading rate $10^{-3} / \mathrm{s}$, and fast unloaded by a certain amount of stress. At the reduced stress $\sigma_{r}$, the specimen is allowed to creep 30 min, during which X-ray diffraction patterns are continuously recorded. The relative reduced stress $R=\sigma_{r} / \sigma_{0}$ is used to compare the transient behaviour of materials with different microstructures.

Figure 2

Figure 2 Schematic representation of a series of conventional stress reduction tests. The specimen is first strained to a pre-defined stress $\sigma_{0}$ at a constant loading rate, followed by a fast stress reduction and creep at a reduced stress $\sigma_{r}$.

\subsubsection{NC Ni}

The results for Ni_35 were reported in Ref. [18]. Here we show the results for Ni_65. The stress reduction tests were carried out at $\sigma_{0}=1.5 \mathrm{GPa}$, which is slightly below the ultimate tensile strength of 1.6 GPa. For both NC Ni batches the total strain produced prior to stress 
reduction is similar. Figure 3 summarizes the stress-dependent transient behaviour for $R$ ranging between 1 to 0.1 : four regimes can be categorized based on the evolution of inelastic strain (Figure 3a) and the change of FWHM of $\{311\}$ diffraction peak (Figure $3 b$ ) during creep periods of $30 \mathrm{~min}$. In Regime I, where the smallest stress drops were conducted, a positive initial inelastic strain rate $\dot{\varepsilon}_{r, i}$ (forward deformation) was measured accompanied with an increase in FWHM. In Regime II, where stress drops were slightly larger, $\dot{\varepsilon}_{r, i}$ remains positive whereas the FWHM initially decreases. After creeping for a few minutes, the FWHM shows some increase for $R=0.91$. Such a non-monotonic change of FWHM has been previously observed for NC Ni_35. Regime III occurs when stress drops were even larger: here the inelastic strain rate is initially negative (backward deformation) and then turns positive when the specimen was crept further (a few minutes more); the FWHM continuously decreases with time. At the largest stress drops, Regime IV is recognized by a significant back flow and a reduction in FWHM during the full creep period.

Figure 3

Figure 3 Results of in situ stress reduction tests on NC Ni_65. First each specimen is loaded to $1.5 \mathrm{GPa}$ at a constant strain rate $\dot{\varepsilon}_{\text {tot }}$ of $10^{-3} / \mathrm{s}$. After a sudden stress drop, (a) the evolution of inelastic strain (the measured strain $\varepsilon$ compared to the strain $\varepsilon_{1}$ at the beginning of the creep) and (b) the change of peak broadening of $\{311\}$ peak (the FWHM compared to the peak broadening $\mathrm{FWHM}_{1}$ at the beginning of the creep) were found to be $R$ dependent. Four regimes can be categorized based on transient responses.

\subsection{2 $\mathrm{NC} \mathrm{Ni}_{50} \mathrm{Fe}_{50}$}

For $\mathrm{NC} \mathrm{Ni}_{50} \mathrm{Fe}_{50}$ the in situ stress reduction tests were carried out after the specimens were strained to either $\sigma_{0}=1.7 \mathrm{GPa}$ or $\sim 1.9 \mathrm{GPa}$. According to the yield criterion defined by Thilly [29], macro-plasticity occurs at both stress levels. For $\sigma_{0}=1.7 \mathrm{GPa}$, where macro- 
plasticity just starts, the evolution of inelastic strain as well as FWHM of the $\{200\}$ peak during 30 min creep are displayed in Figures $4 \mathrm{a}$ and $4 \mathrm{~b}$, respectively. Note that we show here the results for the $\{200\}$ peak because it exhibits qualitatively similar behaviour as the $\{311\}$ peak but with higher signal-to-noise ratio. In contrast to the case of $\mathrm{NC}$ Ni no increase in FWHM is observed. With other words, no Regime I could be found.

Figure 4

Figure $4 \mathrm{NC} \mathrm{Ni}_{50} \mathrm{Fe}_{50}$ : transient responses of in situ conventional stress reduction tests performed at $\sigma_{0}=1.7 \mathrm{GPa}$. After a sudden stress drop, (a) the evolution of inelastic strain (the measured strain $\varepsilon$ compared to the strain $\varepsilon_{1}$ at the beginning of the creep) and (b) the change of peak broadening of $\{200\}$ peak (the FWHM compared to the peak broadening $\mathrm{FWHM}_{1}$ at the beginning of the creep) was $R$ dependent. Three similar regimes as for NC Ni can be found except for Regime I.

For the stress reduction tests series performed at $\sigma_{0} \sim 1.9 \mathrm{GPa}$, a more significant change in $\{200\}$ peak width was detected in comparison to the tests done at $\sigma_{0}=1.7 \mathrm{GPa}$. In addition, the behaviour of the different peak families was not the same, in particular at $\mathrm{R}=1$. For this special case, the evolution of strain as well as FWHM for $\{111\},\{200\}$ and $\{311\}$ diffraction peaks are displayed in Figure 5a. Interestingly, the FWHM for $\{200\}$ peaks exhibits a significantly larger reduction compared to the other diffraction peaks. This peculiar behaviour has been confirmed in multiple experiments (not shown). In order to make a comparison with $\mathrm{NC} \mathrm{Ni}$, Figure $5 \mathrm{~b}$ and $5 \mathrm{c}$ display the results from tests on NC Ni_65 and Ni_35 at $R \sim 1$. In contrast to the case of $\mathrm{NC} \mathrm{Ni}_{50} \mathrm{Fe}_{50}$ the FWHM for all peaks increase with time during the creep periods. For Ni_65 the FWHM of the $\{200\}$ exhibits the smallest change, whereas for Ni_35 this is the case for the $\{111\}$ peak. This is most probably related to the different degree of texture in these two batches (Table 2) and will not be commented further. 
Figure 5

Figure 5 Evolution of inelastic strain and the change of peak broadening for $\{111\},\{200\}$ and $\{311\}$ diffraction peaks during transient creep at $R \sim 1$. Both $\varepsilon$ and FWHM are compared to the values $\varepsilon_{1}$ and $\mathrm{FWHM}_{1}$ at the beginning of the creep. (a) For $\mathrm{NC} \mathrm{Ni}_{50} \mathrm{Fe}_{50}$, the change of peak broadening is peak family dependent; for (b) NC Ni_65 and (c) NC Ni_35, peak width for all peak families increase with time.

\subsection{Stress dependence of the strain rate at constant microstructure}

Assuming the structure after sudden stress drops is "constant", the stress dependence of initial strain rate at constant microstructure can be derived from the creep strain versus time curves. In Figure 6, the normalized forward strain rate $\dot{\varepsilon}_{r} / \dot{\varepsilon}_{0}$ is plotted logarithmically as a function of normalized reduced stress $\sigma_{r} / \sigma_{0}$. Here, $\dot{\varepsilon}_{r}$ is defined as the immediate initial creep rate $\dot{\varepsilon}_{r, i}$ in Regimes I and II $\left(\dot{\varepsilon}_{\text {inel }}>0\right)$, and for Regime III $\left(\dot{\varepsilon}_{\text {inel }}<0\right) \dot{\varepsilon}_{r}$ is a relative maximum $\dot{\varepsilon}_{r, \text { max }}$ when $\dot{\varepsilon}_{\text {inel }}$ turns to positive after anelastic back flow is over. $\dot{\varepsilon}_{0}$ and $\sigma_{0}$ refers to the values just prior to the stress reduction. Although the term "constant structure" is not exact with regard to fast changing parameters such as dislocation density and internal stress distribution, in particular after large stress reductions, it is an acceptable presumption, which allows investigating the individual contributions from multiple deformation mechanisms.

Figure 6

Figure 6 The normalized maximum forward strain rate $\dot{\varepsilon}_{r} / \dot{\varepsilon}_{0}$ is plotted logarithmically as a function of normalized reduced stress $\sigma_{r} / \sigma_{0}$ for (a) $\mathrm{NC} \mathrm{Ni}$ and (b) $\mathrm{NC} \mathrm{Ni} \mathrm{Ni}_{50} \mathrm{Fe}_{50} . \dot{\varepsilon}_{0}$ and $\sigma_{0}$ are the values prior to the stress reduction. Each group of data is fitted by a sum of two exponential functions (dashed lines). The solid line represents the resulting fit. 
Figure 6a displays the stress dependence of the normalized strain rate for NC Ni_65 and compares it with the values obtained for $\mathrm{NC} \mathrm{Ni} 35$ [18]; the colours indicate the four regimes specified in Figure 3. In the case of moderate and large stress drops (Regimes II-III), where the FWHM always decreases immediately, the logarithm of the creep rate $\dot{\varepsilon}_{r}$ is linearly proportional to the stress (left branch). Once entering Regime I where the FWHM continuously increases, the stress dependence of strain rate deviates from linearity and approaches the new linear regime with a steeper slope (right branch). We can consider $\dot{\varepsilon}_{r}$ as a sum of two contributions, related to GB-mediated and dislocation-based processes. This is visualized in Figure $6 \mathrm{a}$ by the solid line, which represents the result of a fit of the experimental data by a sum of two exponential functions. It is clear that these two mechanisms dominate at low and high stress levels, respectively. For equivalent values of $R$ the relative reduced rates $\dot{\varepsilon}_{r} / \dot{\varepsilon}_{0}$ are considerably lower for larger grain sizes. On the other hand, the slopes of the left branches are not so different: 4.6 and 5.0 for Ni_35 and Ni_65, respectively.

\subsection{2 $\mathrm{NC} \mathrm{Ni}_{50} \mathrm{Fe}_{50}$}

Figure $6 \mathrm{~b}$ shows the stress dependence of strain rate after stress drops for $\mathrm{NC} \mathrm{Ni}_{50} \mathrm{Fe}_{50}$; data points obtained after drops from $\sigma_{0}=1.7 \mathrm{GPa}$ and $\sim 1.9 \mathrm{GPa}$ are included. Also here two linear relationships between logarithmic maximum forward rate and reduced stress are observed, although it has to be mentioned that the line with the steeper slope is drawn with only one experimental point. This is because even after a very small drop $2 \%(R=0.98)$, the

strain rate decreases considerably and lies on the linear line from left branch. As it can be seen, the strain rates obtained are lower than those obtained for NC Ni_65 indicated by a steeper slope of 6.5 for the left branch.

\subsection{Repeated transient creep after stress reduction}


In the case of conventional stress reduction tests (section 3.2), a major issue often encountered is that at a low reduced stress where dislocation glide is supressed enough the strain rate becomes so low that the full transient response is not accessible during an in situ measurement. This is visualized in Figure 7: after a large stress reduction the maximum forward strain rate $\dot{\varepsilon}_{r, \max }$ (black dot) continuously decreases under the constant applied stress during the creep periods (indicated by the blue dashed line). As the specimen is crept further, the strain rate drops below typical experimental observable timescales, so that it can hardly approach the new quasi-stationary state (pink solid line) where the dislocation structure (including the structure at the boundaries) has come close to a dynamic equilibrium in terms of defect generation and recovery. In order to overcome this issue a new methodology has been introduced in Ref. [18]. Figure 8 is a schematic representation of this so-called multistep test. After a large stress reduction at $\sigma_{0}$, the applied stress is raised in a series of $35 \mathrm{MPa}$ per step and held for $20 \mathrm{~min}$ at each stress level. The objective is to set a lower bound to the decline of creep rate in each step so that it stays within a certain interval. As indicated by the green dashed line in Figure 7, the new quasi-stationary state can be approached within measurable time by increasing stress at similar strain rates.

Figure 7

Figure 7 Schematic representation of the evolution of strain rates during I. single transient creep in a conventional stress reduction test (blue dashed line) and II. repeated transient creep in a multistep test with each step ending near the creep rate given by the green dashed line. The black dot is the maximum forward strain rate after a large stress reduction. The pink curve represents the quasi-stationary line.

Figure 8 
Figure 8 Schematic representation of a multistep test. After a large stress reduction, the applied stress is stepwise increased. In the present work, each stress level is held constant for 20 min followed by an increment of $\sim 35 \mathrm{MPa}$ per step.

\subsubsection{NC Ni}

An in situ multistep test (Figure 9) on NC Ni_65 was performed when the specimen was first strained to $\sigma_{0}=1.56 \mathrm{GPa}$ with a constant strain rate $\dot{\varepsilon}_{\text {tot }}$ of $10^{-3} / \mathrm{s}$. Figures $9 \mathrm{a}$-e provide an overview of the resulting transient behaviour. Figure 9a shows the inelastic strain-stress relation where the applied stress after a large stress reduction is increased from $0.74 \mathrm{GPa}$ to 1.45 GPa in 20 steps. Figure $9 \mathrm{~b}$ displays the strain rate as a function of inelastic strain. It was observed that at each stress level the continuous decrease in creep rate was interrupted by a small increment of stress and the overall rates were kept within a certain range. In the last step, the strain rate seems to be nearly quasi-stationary after a short decline. Figure $9 \mathrm{~d}$ represents the same rate data as in Figure $9 \mathrm{~b}$ where strain rate is plotted as a function of applied stress. The grey line is taken from the $\dot{\varepsilon}_{r}$-curve (solid line) for NC Ni_65 from Figure 6a assuming the same $\dot{\varepsilon}_{r}-\sigma_{r}$ relationship for $\sigma_{0}=1.56 \mathrm{GPa}$. After a large stress reduction with $R=0.47$, which belongs to Regime III, an anelastic back flow $\left(\dot{\varepsilon}_{\text {inel }}<0\right)$ is detected and afterwards the maximum forward strain rate $\dot{\varepsilon}_{r, \max }$ (red dot) lies on the $\dot{\varepsilon}_{r}$-curve. Each vertical black line represents a continuous decrease in strain rate at a certain stress level. At the highest creep stress, the strain rate ends up with a value (green dot) approaching the pink quasi-stationary line (taken from orange circles in Figure 1), which agrees with the statement from Figure 9b: a new quasi-stationary state is reached in the last step.

The corresponding evolution of the FWHM for the $\{200\}$ (green curve) and $\{311\}$ (blue curve) diffraction peaks is shown in Figure 9c, indicating a non-monotonic change. The FWHM is not only changing during the 20 min creep periods but also upon each stress 
increase. In Figure 9e these two contributions are decoupled; the greens symbols represent the magnitude of the total change of the $\{200\}$ peak broadening during each creep period, and the difference of the peak broadening before and after each $\sim 35 \mathrm{MPa}$ stress increase is plotted by the orange symbols. For the first stress increments, the FWHM decreases while the stress is kept constant during the creep periods. Upon further increasing the stress (after the $5^{\text {th }}$ incremental step, approximately $0.9 \mathrm{GPa}$ ), the FWHM stays constant during the creep periods. Above 1.3 GPa the creep strain produced at each stress level grows and the change of FWHM increases $(>0)$ during creep time. The evolution of the FWHM during the stress changes exhibits a different behaviour (orange symbols in Figure 9e); it is constant but nonzero up to $1.3 \mathrm{GPa}$ and then increases in magnitude. The FWHM of $\{311\}$ peak gives similar results (not shown here). Furthermore, these results are in qualitative agreement with those obtained for NC Ni_35 [18].

Figure 9

Figure 9 Overview of transient behaviour during the in situ multistep tests for Ni_65 (a-e) and $\mathrm{Ni}_{50} \mathrm{Fe}_{50}(\mathrm{f}-\mathrm{j}) .(\mathrm{a}, \mathrm{f})$ The inelastic strain-stress relation; $(\mathrm{b}, \mathrm{g})$ the creep rate, and $(\mathrm{c}, \mathrm{h})$ the FWHM change for $\{200\}$ and $\{311\}$ peaks as a function of inelastic strain; (d,i) creep rate as a function of stress; $(\mathrm{e}, \mathrm{j})$ the overall change of FWHM for $\{200\}$ peaks are decoupled into contributions from 20 min creep periods (green symbols) - the difference of FWHM at the beginning/end of creep, and from stepwise stress increasing (orange symbols) - the difference of FWHM before and after each stress increment of $\sim 35 \mathrm{MPa}$.

\subsection{2 $\mathrm{NC} \mathrm{Ni}_{50} \mathrm{Fe}_{50}$}

The in situ multistep test on $\mathrm{NC} \mathrm{Ni}_{50} \mathrm{Fe}_{50}$ was conducted after straining the specimen to $\sigma_{0} \sim 1.9 \mathrm{GPa}$ with a constant strain rate $\dot{\varepsilon}_{t o t}$ of $10^{-3} / \mathrm{s}$. Figures $9 \mathrm{f}-\mathrm{j}$ provide an overview of the transient response after a stress reduction with $R=0.58$. Figure $9 \mathrm{f}$ shows the inelastic 
strain-stress relation where the reduced stress is stepwise increased from $1.1 \mathrm{GPa}$ to $1.8 \mathrm{GPa}$. Figures $9 \mathrm{~g}$ and $9 \mathrm{i}$ display the strain rates as function of inelastic strain and applied stress. In the latter plot, the grey curve is taken from the $\dot{\varepsilon}_{r}$-curve (solid line) in Figure 6b; the pink line is taken from blue squares in Figure 1, showing that the maximum flow stresses measured at constant strain rates are very similar. After a large stress reduction, the initial strain rate is negative (anelastic back flow) and reaches $\dot{\varepsilon}_{r, \max }$ (red dot) after creeping for a while. The $\dot{\varepsilon}_{r, \max }$ is not far away from the $\dot{\varepsilon}_{r}$-curve. In contrast to $\mathrm{NC} \mathrm{Ni}$, the strain rate in the last step is quite distant from the pink line and showing a continuously decreasing trend. In addition, note that the inelastic strain produced during transients is much less, even for creeping at the highest stress levels.

Figure 9h shows the corresponding evolution of FWHM for $\{200\}$ (green curve) and $\{311\}$ (blue curve) diffraction peaks. It is noted that the overall shape of FWHM curves are similar to that of the inelastic strain-stress relation. This implies that the stepwise increased stress is the main contributor to the change of FWHM during transients. This is further confirmed in Figure 9j, which, similar to the case of Ni_65 (Figure 9e) displays the two contributions of the FWHM. Clearly the change in FWHM is mainly determined by the applied stress, except immediately after the large stress reduction where the change in FWHM also occurs during creep. When increasing the stress levels no significant change in FWHM is observed during the 20 min creep periods.

\section{Discussion}

\subsection{Recovery mechanisms mediated by $G B$}

It is well established that for $\mathrm{NC}$ metals with grain sizes in the range $10-100 \mathrm{~nm}$ plastic deformation is governed by an interplay between dislocation-based and GB-mediated 
deformation mechanisms. MD simulations suggest that GBs in NC metals act as both source and sink for dislocations [30][31][32][33]. During plastic deformation, a dislocation that is emitted from the GB or triple junction (TJ), travels through the entire grain and is eventually absorbed in the neighbouring and opposite GBs. As a consequence, few dislocations remain in the grain interiors and no dislocation network is generated inside the grains. This hypothesis has been confirmed by in situ experiments during X-ray diffraction [34][35] or in a TEM [36][37]. At the same time GB-mediated mechanisms such as GB sliding and migration become more important with decreasing grain size.

Within this model the behaviour of both macroscopic strain and diffraction peak broadening as a function of the magnitude of the stress reduction can be rationalized as follows: the ratio between dislocation-based and GB-mediated mechanisms depends on the magnitude of the stress reduction, resulting in the different regimes that are observed in Figure 3. The interplay between diffraction peak broadening and inlastic strain in these regimes is visualized in Figure 10 for the case of NC Ni_65. A similar trend is observed for NC Ni_35. In Regime I, the applied stress after a small drop is still above the internal stress. Therefore, dislocations will further nucleate and propagate, however at a reduced rate. At the same time, dislocation slip requires GB accommodation processes [38][39][40]. However, as long as the dislocationbased mechanisms still dominate over recovery mechanisms, the diffraction peak broadening exhibits a net increase during transients. After moderate or large stress reductions within Regimes II-IV, the contribution of dislocation activity is suppressed so that GB-mediated mechanisms take a role in which the peak broadening decreases. At the same time, the overall shape of inelastic strain-time curve is determined by the net result of forward flow and backward flow. In Regimes III and IV, the initial negative strain is ascribed to the dominance of back flow that mainly originates from backward motion of dislocations. This is a relatively fast process during which the internal back stresses drops quickly, thereby quickly reducing 
its contribution to backward flow. In contrast, recovery mechanisms mediated by GBs are relatively slow. This kind of processes continue long after the stress reduction and generate forward flow that gradually declines with the progress of recovery as a result of internal stress relaxation.

Figure 10

Figure 10 Change of peak broadening (the FWHM compared to the initial broadening $\mathrm{FWHM}_{00}$ prior to loading) as a function of inelastic strain during creep after stress reduction with $R$ values indicated in the graph. The inset represents a zoom.

\subsection{Influence of grain size}

Overall one can say that the transient behaviour of $\mathrm{Ni} 35$ and $\mathrm{Ni} 65$ is very similar as well as their signature in the diffraction pattern. After medium/large stress drops performed on NC Ni_65, the strain rate associated with GB-mediated mechanisms comes into view and it continues to decrease with strain as was reported in Ref. [18] for Ni_35, for which this behaviour was compared with that of coarse-grained pure metals. Moreover, it is found that the immediate strain rate after such a magnitude of stress drop in Ni_65 is lower than that of Ni_35 but the dependence on the stress drop is not very different: the slope of the normalized reduced strain rate $\dot{\varepsilon}_{r} / \dot{\varepsilon}_{0}$ versus $R$ (Figure 6a) amounts 4.6 for Ni_35 and 5.0 for Ni_65.

The influence of grain size on GB accommodation processes can be estimated from Figure 6 . By extrapolating the linear slope $\dot{\varepsilon}_{r} / \dot{\varepsilon}_{0}$ fitted to the large and medium stress drops to $R=1$, the relative contribution of the GB-mediated processes to the overall strain rate can be obtained. We find that $24 \%$ of the strain rate in Ni_35 comes from GB mediated accommodation mechanisms whereas only $12 \%$ in Ni_65. Assuming that the generated strain is predominantly due to dislocations, a larger number of dislocations is needed in 
Ni_35 [41]. Whether this would change the relative amount of the strain rate between dislocation slip and recovery is unknown. One should not forget that the character of the GBs can be different which can influence the type of accommodation involved as well as the amount required. Also, since NC Ni_65 exhibits a stronger (100) out-of-plane texture than that of NC Ni_35, the influence of texture cannot be excluded. Finally, it is interesting to note that in $\mathrm{Ni}_{50} \mathrm{Fe}_{50}$ with the smallest grain size, only $12 \%$ of the strain rate would come from accommodation mechanisms at $R=1$, suggesting that GB character and alloying play an important role besides the grain size.

\section{$4.3 \mathrm{Ni}_{50} \mathrm{Fe}_{50}$ versus $\mathrm{Ni}$}

Figure 11 summarizes the total change of FWHM versus the total change of inelastic strain during 30 min of creep for $\mathrm{NC} \mathrm{Ni} 35$, Ni_65, and $\mathrm{Ni}_{50} \mathrm{Fe}_{50}$. The data points framed in the black squares represent the values measured at relative reduced stress $R=1$. For NC Ni we observe the expected behaviour: with increasing magnitude of stress reduction (decreasing $R$ ) less plastic strain is produced and the peak broadening decreases accordingly. For $R$ values below $\sim 0.5$ the FWHM decreases during the creep periods because forward dislocation glide is largely suppressed and recovery mechanisms prevail, as discussed in the previous sections. For $\mathrm{Ni}_{50} \mathrm{Fe}_{50}$ the opposite trend is observed: at $R=1$ the largest reduction of peak broadening is observed, which reduces with decreasing values of $R$. With other words, more plastic strain goes hand in hand with more reduction of the peak broadening.

\section{Figure 11}

Figure 11 After 30 min creep, the change of peak broadening $\left(\mathrm{FWHM}_{30 \mathrm{~min}}\right.$ compared to the broadening $\mathrm{FWHM}_{1}$ at the beginning of the creep) is plotted versus the change of inelastic strain generated during that period ( $\varepsilon_{30 \min }$ compared to $\left.\varepsilon_{1}\right)$. The data points framed in the 
black square represent the values measured at a relative reduced stress $R=1 ; R$ decreases along the straight lines from the right side of plot to the left.

There are several possible reasons for the observed differences between $\mathrm{NC} \mathrm{Ni}$ and $\mathrm{Ni}_{50} \mathrm{Fe}_{50}$. The most obvious one is related to the effect of solutes. It was shown that in this batch of NC $\mathrm{Ni}_{50} \mathrm{Fe}_{50}$ the $\mathrm{Fe}$ atoms are in solute solution in the f.c.c. Ni matrix, however with local compositional fluctuations at the GBs and in the grain interiors [19]. Solutes are known to affect dislocation mobility [42]. The addition of Fe to the Ni matrix leads to a large reduction of the shear modulus, which in turn results in a softening effect [20][43]. As a consequence, the strength of this $\mathrm{Ni}_{50} \mathrm{Fe}_{50}$ batch is similar to that of $\mathrm{NC} \mathrm{Ni} 35$, despite its smaller grain size and the presence of solutes. On the other hand, solutes may induce strain aging effects, i.e. solutes diffuse to mobile dislocations that are (temporarily) pinned, leading to an increase of the required stress to unpin them. The presence of an upper/lower yield point upon reloading or changing the strain rate is an indication of such strain aging effects [20]. Also the stress reduction tests presented in this work give the same indication. This hypothesis is further strengthened by Figure 12, which shows for both $\mathrm{NC} \mathrm{Ni \_ 35}$ and $\mathrm{Ni}_{50} \mathrm{Fe}_{50}$ the evolution of strain rate as a function of inelastic strain generated during creep after stress reductions with $R=1$ and $R=0.9$. Three remarkable differences can be observed: (1) the slopes for $\mathrm{Ni}_{50} \mathrm{Fe}_{50}$ are much steeper compared to $\mathrm{Ni}$; (2) for $\mathrm{Ni}_{50} \mathrm{Fe}_{50}$ the initial strain rate at $R=0.9$ is very much reduced compared to $R=1$ (nearly two orders of magnitude), which is much less pronounced for the case of $\mathrm{Ni}$; (3) at $R=0.9$ the slope for $\mathrm{Ni}_{50} \mathrm{Fe}_{50}$ is significantly steeper compared to $R=1$, which is also much less pronounced for the case of $\mathrm{Ni}$. All these observations point towards a mechanism in $\mathrm{Ni}_{50} \mathrm{Fe}_{50}$ where dislocation glide is suppressed effectively when changing from constant strain rate to constant stress (even at $R=1$ ). This may also explain the opposite trend observed for $\mathrm{Ni}_{50} \mathrm{Fe}_{50}$ in Figure 11: as dislocations are 
pinned by solutes the main contribution to the change in FWHM arises from recovery, which decreases with decreasing $R$.

Figure 12

Figure 12 The evolution of normalized inelastic strain rate $\dot{\varepsilon}_{\text {inel }} / \dot{\varepsilon}_{0}$ as a function of inelastic strain generated during creep after stress reductions with $R=1$ and $R=0.9$ : Ni_35 and $\mathrm{Ni}_{50} \mathrm{Fe}_{50}$ are respectively denoted as pink and blue symbols

Other arguments can be used to explain the different behaviour in Figure 11. NC Ni-Fe is known to exhibit grain growth during plastic deformation [26][28][44][45][46][47]. Therefore, the reduction of the FWHM during creep after stress reduction may be interpreted as an indication for grain growth. The reduction of the FWHM at $R=1$ would correspond to an increase of the average grain size by $\sim 7 \%(1 \mathrm{~nm})$ in the direction perpendicular to the loading direction. With decreasing values of $R$ grain growth is reduced, leading to a lower decrease of the FWHM. Such a large grain growth is however unlikely, as only $0.5 \%$ strain is produced during creep at $R=1\left(\sigma_{0}=1.7 \mathrm{GPa}\right)$.

Moreover, for the case of $\mathrm{Ni}_{50} \mathrm{Fe}_{50}$ we also need to consider the effect of stacking fault energy (SFE). It is known that the addition of soluble alloying elements in f.c.c. metals decreases the SFE [48]. In the case of Ni-Fe alloys, the SFE is decreasing approximately linearly with the addition of Fe to Ni matrix [49][50]. As a result, the low SFE facilitates the emission of partial dislocations over full dislocations. Furthermore, Ni-Fe is known to exhibit a high density of growth twins [20][26][27][44][51]. Under certain conditions a reduction of such growth twins has been observed. For instance, Li et al. [26] found a reduction of twin density after cold rolling of $\mathrm{Ni}-18 \mathrm{wt} \% \mathrm{Fe}$, Cheng et al. [27][44] reported on a similar observation for $\mathrm{Ni}-20 \mathrm{wt} \% \mathrm{Fe}$ after substantial deformation under dynamic loading and after the cyclic deformation with overall plastic strain $<2 \%$, and so did the work of $\mathrm{S}$. Ni et al. where Ni- 
$20 \mathrm{wt} \% \mathrm{Fe}$ was under severe plastic deformation. Therefore, the inverse trend for the FWHM observed in Figure 11 for $\mathrm{Ni}_{50} \mathrm{Fe}_{50}$ may also be attributed to detwinning, which would result in an increase of the X-ray coherent scattering length and, consequently, a decrease in peak broadening. With decreasing values of $R$ the detwinning mechanism is effectively reduced.

The multistep tests experiments on $\mathrm{Ni}$ and $\mathrm{Ni}_{50} \mathrm{Fe}_{50}$ (Figure $9 \mathrm{e}$ and $9 \mathrm{j}$ ) reveal a clear dependence of the FWHM on the applied stress; each load step leads to an immediate change in FWHM. For Ni the FWHM decreases at low stress levels during the creep period that follows each step, showing that recovery is still the most important contributor. At higher stress levels the FWHM increases during the 20 min creep periods, indicative for dislocation slip. This is in good agreement with the result of the regular stress reduction tests. For $\mathrm{Ni}_{50} \mathrm{Fe}_{50}$ the FWHM remains constant during creep at low stress levels (except for the first creep period after stress reduction) and even slightly decreases at higher stress levels. This indicates that the deformation mechanism responsible for the reduction of the FWHM (recovery, de-twinning/grain growth) is active at high stress levels.

Question remains why for $\mathrm{Ni}_{50} \mathrm{Fe}_{50}$ the FWHM only increases upon each increase of the applied load and not during the creep period. In situ tensile experiments on $\mathrm{Ni}_{50} \mathrm{Fe}_{50}$ [20] have revealed that during regular monotonic loading the FWHM hardly increases and that after unloading the FWHM is strongly reduced compared to the initial state. These results, together with those reported in this work, indicate that for $\mathrm{Ni}_{50} \mathrm{Fe}_{50}$ dislocation-based plasticity is easily suppressed and that recovery processes are very active. The increase of the FWHM as a function of applied stress may therefore be mainly related to an increase of the width of the distribution of intergranular strains within a grain family, rather than by an increase in dislocation density.

\subsection{Activation volume and internal stress}


As has been shown, both dislocation glide and GB-mediated recovery contribute to the plastic strain. As a consequence, the activation volume derived traditionally from the basic assumption of only thermally activated dislocation glide should be taken in caution. Nevertheless, one may estimate an "apparent" activation volume of thermally activated dislocation motion using equation $V_{1}=\sqrt{3} k T \cdot\left(d \ln \dot{\varepsilon}_{r} / d \sigma_{r}\right)_{\sigma_{r}=\sigma_{0}}$ where $\dot{\varepsilon}_{r}$ is the experimentally measured reduced strain rate. We find $V_{1}=9 b^{3}$ and $32 b^{3}$ for NC Ni_35 and NC Ni_65, respectively. The strain rate sensitivity is determined as $\mathrm{m}=0.028$ and 0.015 , respectively. Overall, these values present the same magnitude as the values reported in Refs. $[2][3][4][52][53][54]$. Compared to their CG counterparts, NC materials exhibit ten times higher strain rate sensitivity and a much lower activation volume than those typically observed for conventional forest dislocation cutting mechanisms (of the order of 100$1000 \mathrm{~b}^{3}$ ). A mechanistic model that partial or perfect dislocations from stress concentrations at a grain boundary or twin boundary in NC materials has been presented by Asaro et al. to rationalize these experimentally determined values [55]. Our results suggest that the enhanced strain rate sensitivity may be in part influenced by the presence of GB-mediated processes. Lower strain rates offer more time to produce positive strain via GB accommodation mechanisms, where strongly thermal activated processes, such as, for instance, dislocation climb at GBs may play an important role [4][41]. When strain aging is present the conditions of constant structure may have been strongly violated, as the solute concentration in relation to the mobile dislocation density is strain rate dependent. This questions the validity of using stress reduction tests for the case of $\mathrm{Ni}_{50} \mathrm{Fe}_{50}$.

In Ref. [11] the magnitude of the internal stress was estimated from conventional ex situ stress reduction tests. It is assumed that the applied stress equals the internal stress when the initial creep rate immediately after a stress drop becomes zero [1][9][10][11]. However, the in situ tests presented in this work suggest that GB-mediated plasticity may also contribute 
significantly to the strain rate. As a consequence, the values of the internal stress are presumably underestimated. A potential other criterion to find the internal stress is to assume that the effective stress on the dislocations becomes zero for stress drops where the $\dot{\varepsilon}_{r}-\sigma_{r}$ curve in Figure 6a deviates from linearity. For the Ni samples presented in this work the internal stress would be about $80 \%$ of the applied stress $\sigma_{0}$ for $\mathrm{NC} \mathrm{Ni} 35$ and $90 \%$ for NC Ni_65.

\section{Conclusions}

In situ stress reduction tests performed on electro-deposited NC Ni with grain sizes of $35 \mathrm{~nm}$ and $65 \mathrm{~nm}$ and on $\mathrm{Ni}_{50} \mathrm{Fe}_{50}$ with a $15 \mathrm{~nm}$ grain size provide evidence that GB-mediated processes play an important role in the control of the strength evolution and the generation of the plastic strain. This result has a significant consequence for the parameters of thermally activated glide of dislocations, such as internal stress and activation volume, which are traditionally derived from stress/strain rate change tests.

The results for both $\mathrm{Ni}$ batches are qualitatively in good agreement. It was found that the relative contribution of the GB-mediated processes to the overall strain rate is larger in $\mathrm{NC}$ Ni_35 than in NC Ni_65. $\mathrm{NC} \mathrm{Ni}_{50} \mathrm{Fe}_{50}$ exhibits a different behaviour in comparison to $\mathrm{NC} \mathrm{Ni}$ : when the specimen was crept at very high stress levels either in a conventional stress reduction test or a multistep test, the peak width hardly increases or even decreases with time. This is usually accompanied with less plastic strain produced during the same creep period. This observation can be interpreted as superposition effects from alloying and grain size. There are several possibilities to explain this behaviour, which includes strain aging, grain growth and detwinning.

\section{Acknowledgements}


The authors gratefully acknowledge the Swiss National Science Foundation for financial support (200021_137881).

\section{Reference}

[1] D. Caillard, J.L. Martin, Thermally Activated Mechanisms in Crystal Plasticity, Elsevier, 2003.

[2] Y.M. Wang, A.V. Hamza, E. Ma, Temperature-dependent strain rate sensitivity and activation volume of nanocrystalline Ni, Acta Mater. 54 (2006) 2715-2726. doi:10.1016/j.actamat.2006.02.013.

[3] V. Maier, K. Durst, J. Mueller, B. Backes, H.W. Höppel, M. Göken, Nanoindentation strain-rate jump tests for determining the local strain-rate sensitivity in nanocrystalline $\mathrm{Ni}$ and ultrafine-grained Al, J. Mater. Res. 26 (2011) 1421-1430. doi:10.1557/jmr.2011.156.

[4] Y.J. Li, J. Mueller, H.W. Höppel, M. Göken, W. Blum, Deformation kinetics of nanocrystalline nickel, Acta Mater. 55 (2007) 5708-5717. doi:10.1016/j.actamat.2007.06.036.

[5] P. Spätig, J. Bonneville, J.-L. Martin, A new method for activation volume measurements: application to Ni3(Al,Hf), Mater. Sci. Eng. A. 167 (1993) 73-79. doi:10.1016/09215093(93)90339-G.

[6] T. Kruml, O. Coddet, J.L. Martin, About the determination of the thermal and athermal stress components from stress-relaxation experiments, Acta Mater. 56 (2008) 333-340. doi:10.1016/j.actamat.2007.09.027.

[7] Y.M. Wang, E. Ma, On the origin of ultrahigh cryogenic strength of nanocrystalline metals, Appl. Phys. Lett. 85 (2004) 2750-2752. doi:10.1063/1.1799238. 
[8] F. Dalla Torre, P. Spätig, R. Schäublin, M. Victoria, Deformation behaviour and microstructure of nanocrystalline electrodeposited and high pressure torsioned nickel, Acta Mater. 53 (2005) 2337-2349. doi:10.1016/j.actamat.2005.01.041.

[9] T. Kruml, O. Coddet, J.-L. Martin, About stress reduction experiments during constant strain-rate deformation tests, Z. Für Met. 96 (2005) 589-594. doi:10.3139/146.101075.

[10] T. Kruml, O. Coddet, J.L. Martin, The investigation of internal stress fields by stress reduction experiments, Mater. Sci. Eng. A. 387-389 (2004) 72-75. doi:10.1016/j.msea.2004.01.066.

[11] S.V. Petegem, S. Brandstetter, H.V. Swygenhoven, J.-L. Martin, Internal and effective stresses in nanocrystalline electrodeposited Ni, Appl. Phys. Lett. 89 (2006) 73102. doi:10.1063/1.2336726.

[12] W. Müller, M. Biberger, W. Blum, Subgrain-boundary migration during creep of lif III. Stress reduction experiments, Philos. Mag. A. 66 (1992) 717-728. doi:10.1080/01418619208201586.

[13] S. Mekala, P. Eisenlohr, W. Blum, Control of dynamic recovery and strength by subgrain boundaries - Insights from stress-change tests on CaF2 single crystals, Philos. Mag. 91 (2011) 908-931. doi:10.1080/14786435.2010.535324.

[14] J. Hausselt, W. Blum, Dynamic recovery during and after steady state deformation of Al-11wt\%Zn, Acta Metall. 24 (1976) 1027-1039. doi:10.1016/0001-6160(76)90133-4.

[15] W. Blum, A. Rosen, A. Cegielska, J.L. Martin, Two mechanisms of dislocation motion during creep, Acta Metall. 37 (1989) 2439-2453. doi:10.1016/00016160(89)90041-2

[16] W. Blum, S. Vogler, M. Biberger, A.K. Mukherjee, Stress dependence of the creep rate at constant dislocation structure, Mater. Sci. Eng. A. 112 (1989) 93-106. doi:10.1016/0921-5093(89)90348-1. 
[17] M. Biberger, J.C. Gibeling, Analysis of creep transients in pure metals following stress changes, Acta Metall. Mater. 43 (1995) 3247-3260. doi:10.1016/09567151(95)00052-W.

[18] Z. Sun, S. Van Petegem, A. Cervellino, K. Durst, W. Blum, H. Van Swygenhoven, Dynamic recovery in nanocrystalline Ni, Acta Mater. 91 (2015) 91-100. doi:10.1016/j.actamat.2015.03.033.

[19] S. Van Petegem, J. Zimmermann, S. Brandstetter, X. Sauvage, M. Legros, H. Van Swygenhoven, Microstructure and deformation mechanisms in nanocrystalline Ni-Fe. Part I. Microstructure, Acta Mater. 61 (2013) 5835-5845. doi:10.1016/j.actamat.2013.06.031.

[20] S. Van Petegem, J. Zimmermann, H. Van Swygenhoven, Microstructure and deformation mechanisms in nanocrystalline Ni-Fe. Part II. In situ testing during X-ray diffraction, Acta Mater. 61 (2013) 5846-5856. doi:10.1016/j.actamat.2013.06.029.

[21] P.R. Willmott, D. Meister, S.J. Leake, M. Lange, A. Bergamaschi, M. Böge, M. Calvi, C. Cancellieri, N. Casati, A. Cervellino, Q. Chen, C. David, U. Flechsig, F. Gozzo, B. Henrich, S. Jäggi-Spielmann, B. Jakob, I. Kalichava, P. Karvinen, J. Krempasky, A. Lüdeke, R. Lüscher, S. Maag, C. Quitmann, M.L. Reinle-Schmitt, T. Schmidt, B. Schmitt, A. Streun, I. Vartiainen, M. Vitins, X. Wang, R. Wullschleger, The Materials Science beamline upgrade at the Swiss Light Source, J. Synchrotron Radiat. 20 (2013) 667-682. doi:10.1107/S0909049513018475.

[22] S. Van Petegem, S. Brandstetter, B. Schmitt, H. Van Swygenhoven, Creep in nanocrystalline Ni during X-ray diffraction, Scr. Mater. 60 (2009) 297-300. doi:10.1016/j.scriptamat.2008.10.034. 
[23] K. Zhang, J.R. Weertman, J.A. Eastman, Rapid stress-driven grain coarsening in nanocrystalline $\mathrm{Cu}$ at ambient and cryogenic temperatures, Appl. Phys. Lett. 87 (2005) 61921. doi:10.1063/1.2008377.

[24] D.S. Gianola, S. Van Petegem, M. Legros, S. Brandstetter, H. Van Swygenhoven, K.J. Hemker, Stress-assisted discontinuous grain growth and its effect on the deformation behavior of nanocrystalline aluminum thin films, Acta Mater. 54 (2006) 2253-2263. doi:10.1016/j.actamat.2006.01.023.

[25] J. Lohmiller, M. Grewer, C. Braun, A. Kobler, C. Kübel, K. Schüler, V. Honkimäki, H. Hahn, O. Kraft, R. Birringer, P.A. Gruber, Untangling dislocation and grain boundary mediated plasticity in nanocrystalline nickel, Acta Mater. 65 (2014) 295-307. doi:10.1016/j.actamat.2013.10.071.

[26] L. Li, T. Ungár, Y.D. Wang, J.R. Morris, G. Tichy, J. Lendvai, Y.L. Yang, Y. Ren, H. Choo, P.K. Liaw, Microstructure evolution during cold rolling in a nanocrystalline $\mathrm{Ni}-\mathrm{Fe}$ alloy determined by synchrotron X-ray diffraction, Acta Mater. 57 (2009) 4988-5000. doi:10.1016/j.actamat.2009.07.002.

[27] S. Cheng, Y. Zhao, Y. Guo, Y. Li, Q. Wei, X.-L. Wang, Y. Ren, P.K. Liaw, H. Choo, E.J. Lavernia, High Plasticity and Substantial Deformation in Nanocrystalline NiFe Alloys Under Dynamic Loading, Adv. Mater. 21 (2009) 5001-5004. doi:10.1002/adma.200901991.

[28] S. Ni, Y.B. Wang, X.Z. Liao, S.N. Alhajeri, H.Q. Li, Y.H. Zhao, E.J. Lavernia, S.P. Ringer, T.G. Langdon, Y.T. Zhu, Strain hardening and softening in a nanocrystalline NiFe alloy induced by severe plastic deformation, Mater. Sci. Eng. A. 528 (2011) 33983403. doi:10.1016/j.msea.2011.01.017

[29] L. Thilly, S.V. Petegem, P.-O. Renault, F. Lecouturier, V. Vidal, B. Schmitt, H.V. Swygenhoven, A new criterion for elasto-plastic transition in nanomaterials: Application 
to size and composite effects on $\mathrm{Cu}-\mathrm{Nb}$ nanocomposite wires, Acta Mater. 57 (2009) 3157-3169. doi:10.1016/j.actamat.2009.03.021.

[30] J. Schiøtz, K.W. Jacobsen, A Maximum in the Strength of Nanocrystalline Copper, Science. 301 (2003) 1357-1359. doi:10.1126/science.1086636.

[31] V. Yamakov, D. Wolf, S.R. Phillpot, A.K. Mukherjee, H. Gleiter, Deformationmechanism map for nanocrystalline metals by molecular-dynamics simulation, Nat. Mater. 3 (2004) 43-47. doi:10.1038/nmat1035.

[32] H. Van Swygenhoven, P.M. Derlet, A. Hasnaoui, Atomic mechanism for dislocation emission from nanosized grain boundaries, Phys. Rev. B. 66 (2002) 24101. doi:10.1103/PhysRevB.66.024101.

[33] H. Van Swygenhoven, P.M. Derlet, A.G. Frøseth, Nucleation and propagation of dislocations in nanocrystalline fcc metals, Acta Mater. 54 (2006) 1975-1983. doi:10.1016/j.actamat.2005.12.026.

[34] Z. Budrovic, H. Van Swygenhoven, P.M. Derlet, S. Van Petegem, B. Schmitt, Plastic Deformation with Reversible Peak Broadening in Nanocrystalline Nickel, Science. 304 (2004) 273-276. doi:10.1126/science.1095071.

[35] Z. Budrovic, S.V. Petegem, P.M. Derlet, B. Schmitt, H.V. Swygenhoven, E. Schafler, M. Zehetbauer, Footprints of deformation mechanisms during in situ X-ray diffraction: Nanocrystalline and ultrafine grained Ni, Appl. Phys. Lett. 86 (2005) 231910. doi:10.1063/1.1947385.

[36] M. Legros, B.R. Elliott, M.N. Rittner, J.R. Weertman, K.J. Hemker, Microsample tensile testing of nanocrystalline metals, Philos. Mag. A. 80 (2000) 1017-1026. doi:10.1080/01418610008212096. 
[37] Z.W. Shan, J.M.K. Wiezorek, E.A. Stach, D.M. Follstaedt, J.A. Knapp, S.X. Mao, Dislocation Dynamics in Nanocrystalline Nickel, Phys. Rev. Lett. 98 (2007) 95502. doi:10.1103/PhysRevLett.98.095502.

[38] H. Van Swygenhoven, P.M. Derlet, Grain-boundary sliding in nanocrystalline fcc metals, Phys. Rev. B. 64 (2001) 224105. doi:10.1103/PhysRevB.64.224105.

[39] H. Van Swygenhoven, A. Caro, D. Farkas, A molecular dynamics study of polycrystalline fcc metals at the nanoscale: grain boundary structure and its influence on plastic deformation, Mater. Sci. Eng. A. 309-310 (2001) 440-444. doi:10.1016/S09215093(00)01794-9.

[40] A. Hasnaoui, H. Van Swygenhoven, P.M. Derlet, Cooperative processes during plastic deformation in nanocrystalline fcc metals: A molecular dynamics simulation, Phys. Rev. B. 66 (2002) 184112. doi:10.1103/PhysRevB.66.184112.

[41] W. Blum, P. Eisenlohr, Dislocation mechanics of creep, Mater. Sci. Eng. A. 510-511 (2009) 7-13. doi:10.1016/j.msea.2008.04.110.

[42] H. Neuhäuser, C. Schwink, Solid Solution Strengthening, in: Mater. Sci. Technol., Wiley-VCH Verlag GmbH \& Co. KGaA, 2006. http://onlinelibrary.wiley.com/doi/10.1002/9783527603978.mst0052/abstract (accessed March 29, 2016).

[43] T.J. Rupert, J.C. Trenkle, C.A. Schuh, Enhanced solid solution effects on the strength of nanocrystalline alloys, Acta Mater. 59 (2011) 1619-1631. doi:10.1016/j.actamat.2010.11.026.

[44] S. Cheng, Y. Zhao, Y. Wang, Y. Li, X.-L. Wang, P.K. Liaw, E.J. Lavernia, Structure Modulation Driven by Cyclic Deformation in Nanocrystalline NiFe, Phys. Rev. Lett. 104 (2010) 255501. doi:10.1103/PhysRevLett.104.255501. 
[45] G.J. Fan, L.F. Fu, H. Choo, P.K. Liaw, N.D. Browning, Uniaxial tensile plastic deformation and grain growth of bulk nanocrystalline alloys, Acta Mater. 54 (2006) 4781-4792. doi:10.1016/j.actamat.2006.06.016.

[46] Y.B. Wang, J.C. Ho, X.Z. Liao, H.Q. Li, S.P. Ringer, Y.T. Zhu, Mechanism of grain growth during severe plastic deformation of a nanocrystalline Ni-Fe alloy, Appl. Phys. Lett. 94 (2009) 11908. doi:10.1063/1.3065025.

[47] S. Ni, Y.B. Wang, X.Z. Liao, S.N. Alhajeri, H.Q. Li, Y.H. Zhao, E.J. Lavernia, S.P. Ringer, T.G. Langdon, Y.T. Zhu, Grain growth and dislocation density evolution in a nanocrystalline Ni-Fe alloy induced by high-pressure torsion, Scr. Mater. 64 (2011) 327330. doi:10.1016/j.scriptamat.2010.10.027.

[48] L.E. Murr, Interfacial phenomena in metals and alloys, (1975). http://inis.iaea.org/Search/search.aspx?orig_q=RN:7236335 (accessed March 17, 2016).

[49] W. Charnock, J. Nutting, The Effect of Carbon and Nickel upon the Stacking-Fault Energy of Iron, Met. Sci. J. 1 (1967) 123-127. doi:10.1179/msc.1967.1.1.123.

[50] R.E. Schramm, R.P. Reed, Stacking fault energies of fcc fe-Ni alloys by x-ray diffraction line profile analysis, Metall. Trans. A. 7 (1976) 359-363. doi:10.1007/BF02642831.

[51] J.D. Giallonardo, G. Avramovic-Cingara, G. Palumbo, U. Erb, Microstrain and growth fault structures in electrodeposited nanocrystalline $\mathrm{Ni}$ and $\mathrm{Ni}-\mathrm{Fe}$ alloys, J. Mater. Sci. 48 (2013) 6689-6699. doi:10.1007/s10853-013-7469-4.

[52] X. Shen, J. Lian, Z. Jiang, Q. Jiang, High strength and high ductility of electrodeposited nanocrystalline Ni with a broad grain size distribution, Mater. Sci. Eng. A. 487 (2008) 410-416. doi:10.1016/j.msea.2007.10.018. 
[53] C.D. Gu, J.S. Lian, Q. Jiang, W.T. Zheng, Experimental and modelling investigations on strain rate sensitivity of an electrodeposited $20 \mathrm{~nm}$ grain sized Ni, J. Phys. Appl. Phys. 40 (2007) 7440. doi:10.1088/0022-3727/40/23/027.

[54] F. Dalla Torre, P. Spätig, R. Schäublin, M. Victoria, Deformation behaviour and microstructure of nanocrystalline electrodeposited and high pressure torsioned nickel, Acta Mater. 53 (2005) 2337-2349. doi:10.1016/j.actamat.2005.01.041.

[55] R.J. Asaro, S. Suresh, Mechanistic models for the activation volume and rate sensitivity in metals with nanocrystalline grains and nano-scale twins, Acta Mater. 53 (2005) 3369-3382. doi:10.1016/j.actamat.2005.03.047. 


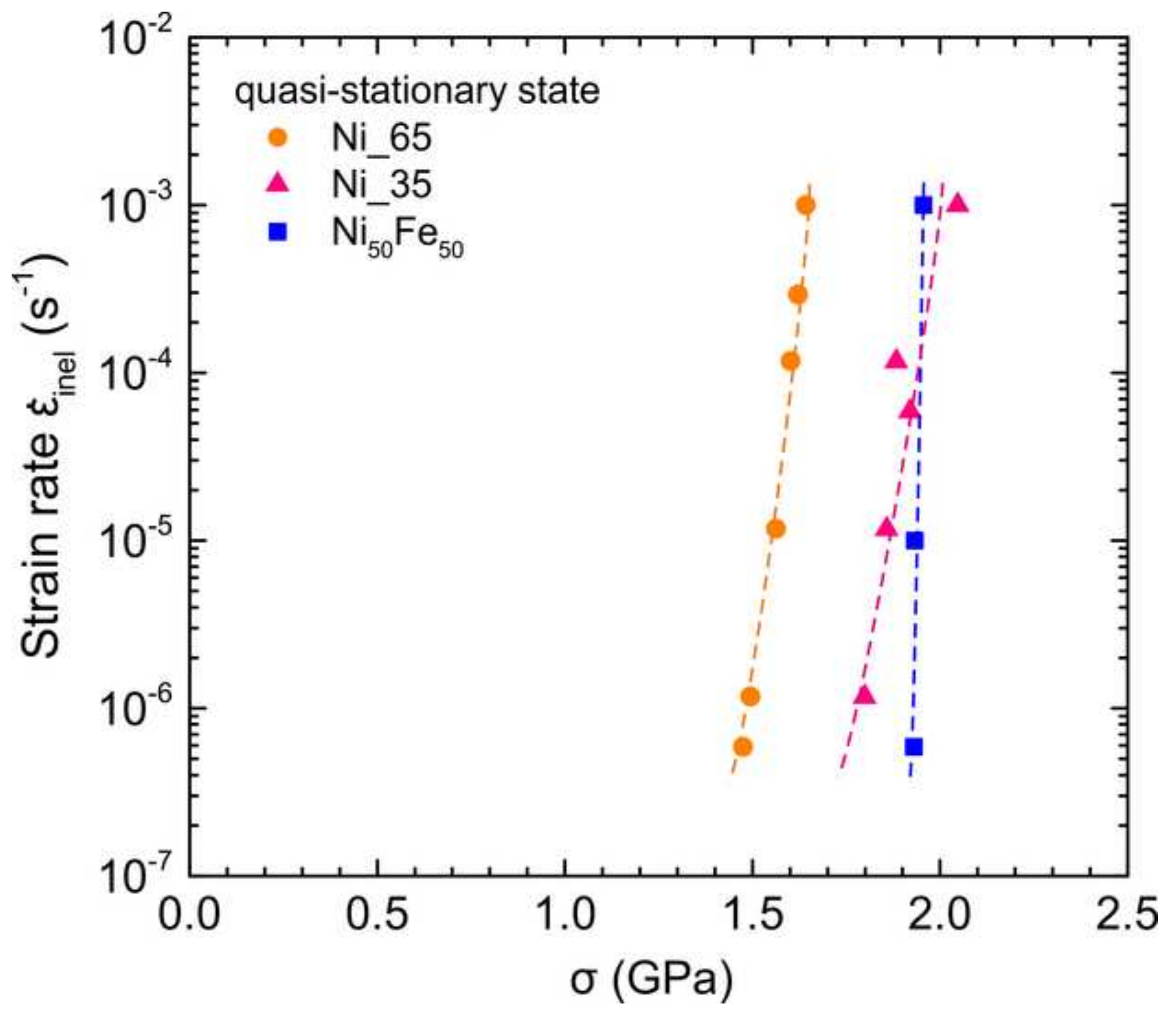




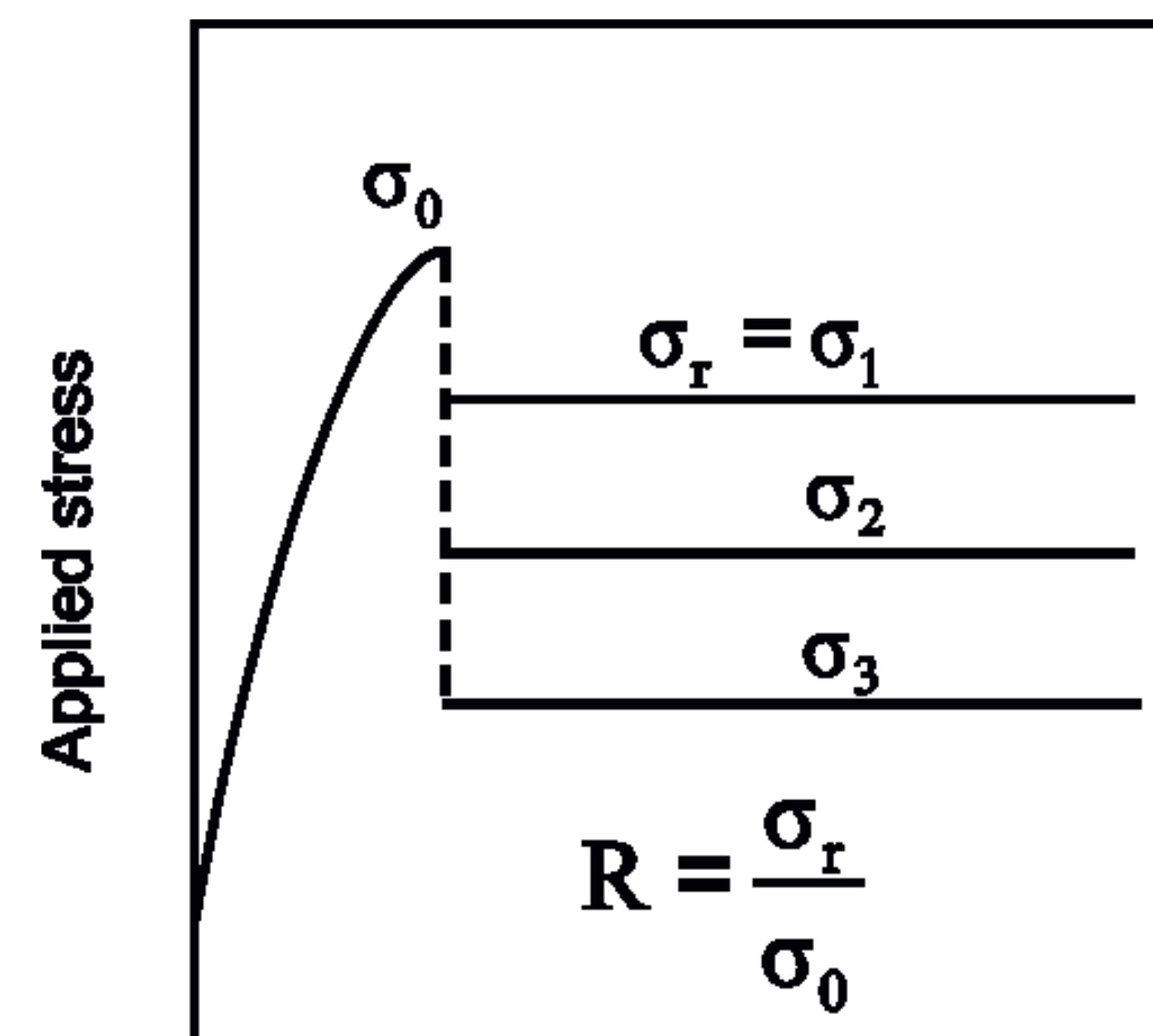

Time 
(a)

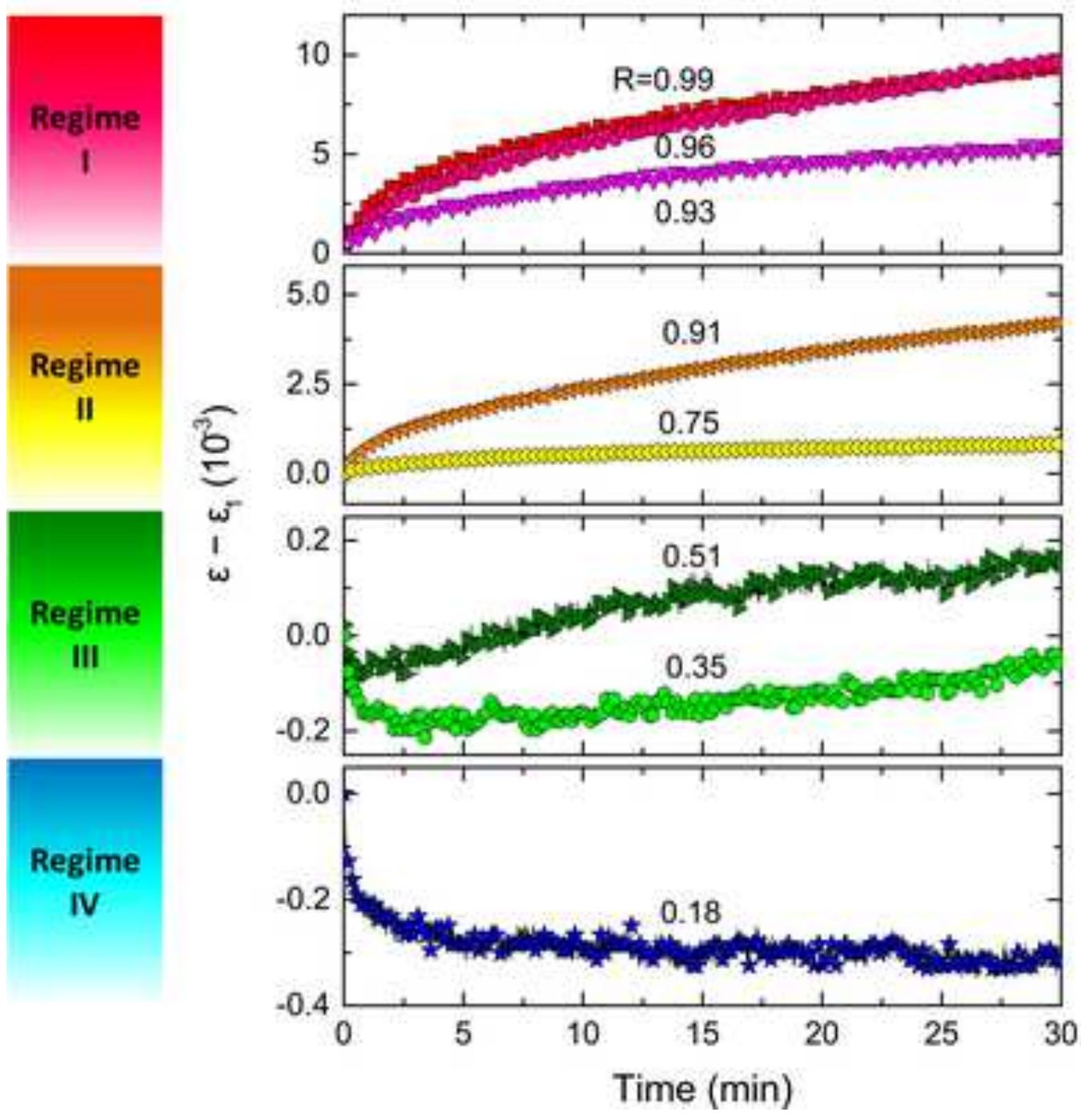

(b)

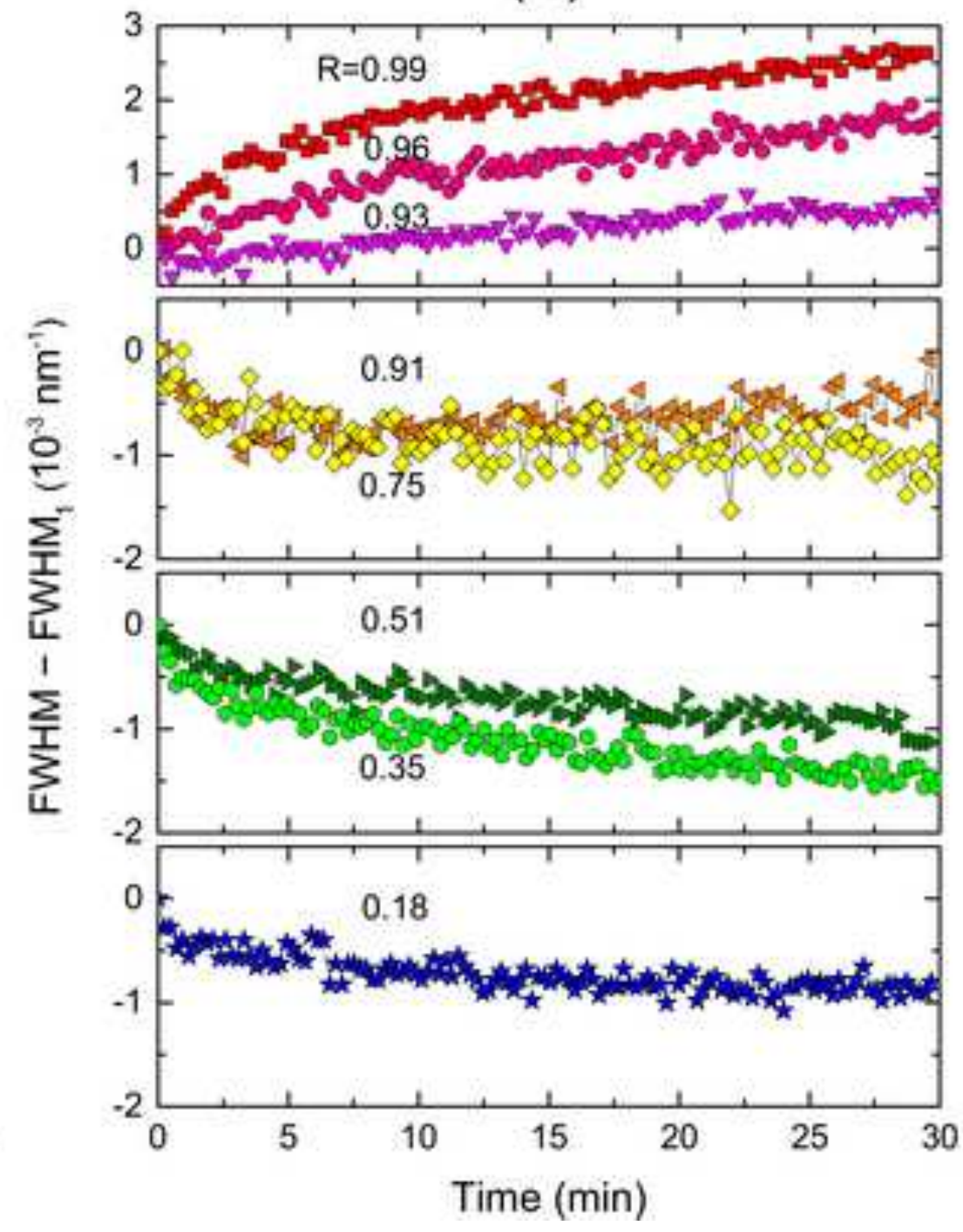


(a)

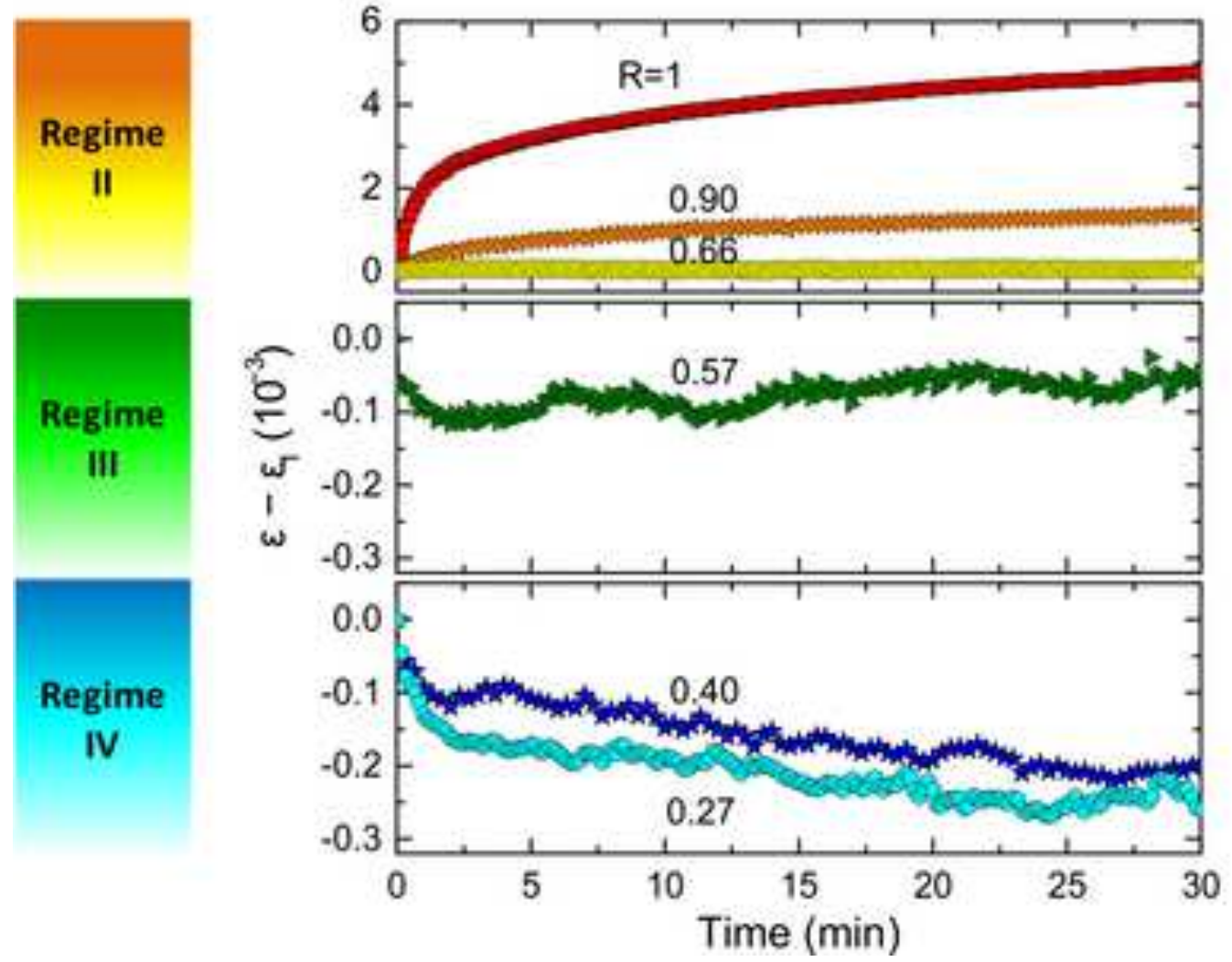

(b)

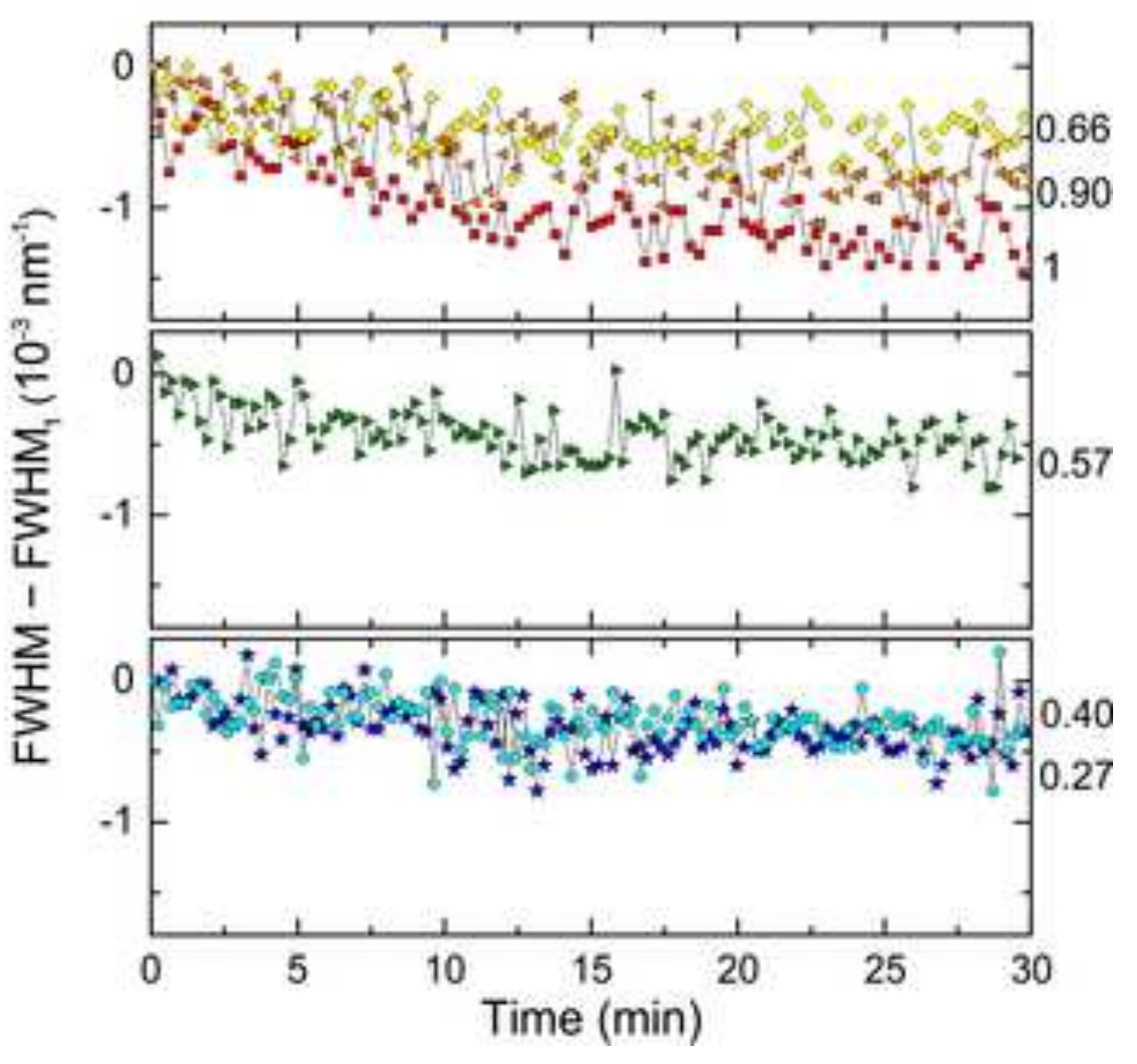


(a)

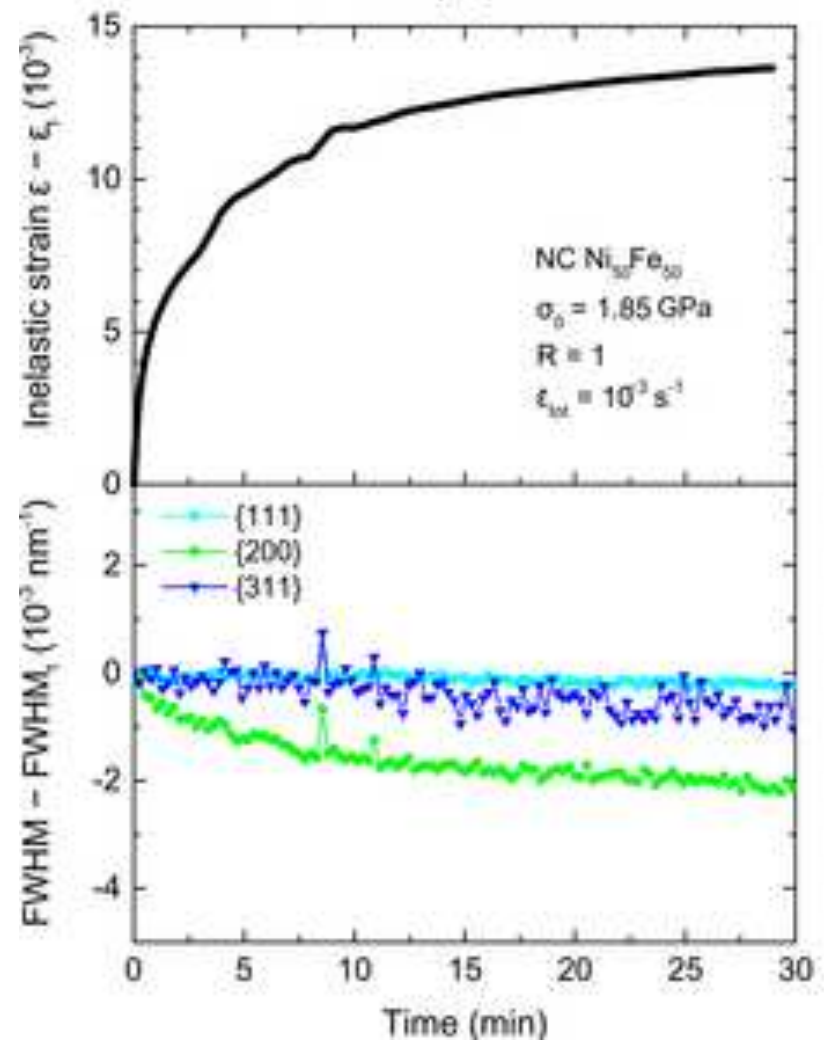

(b)

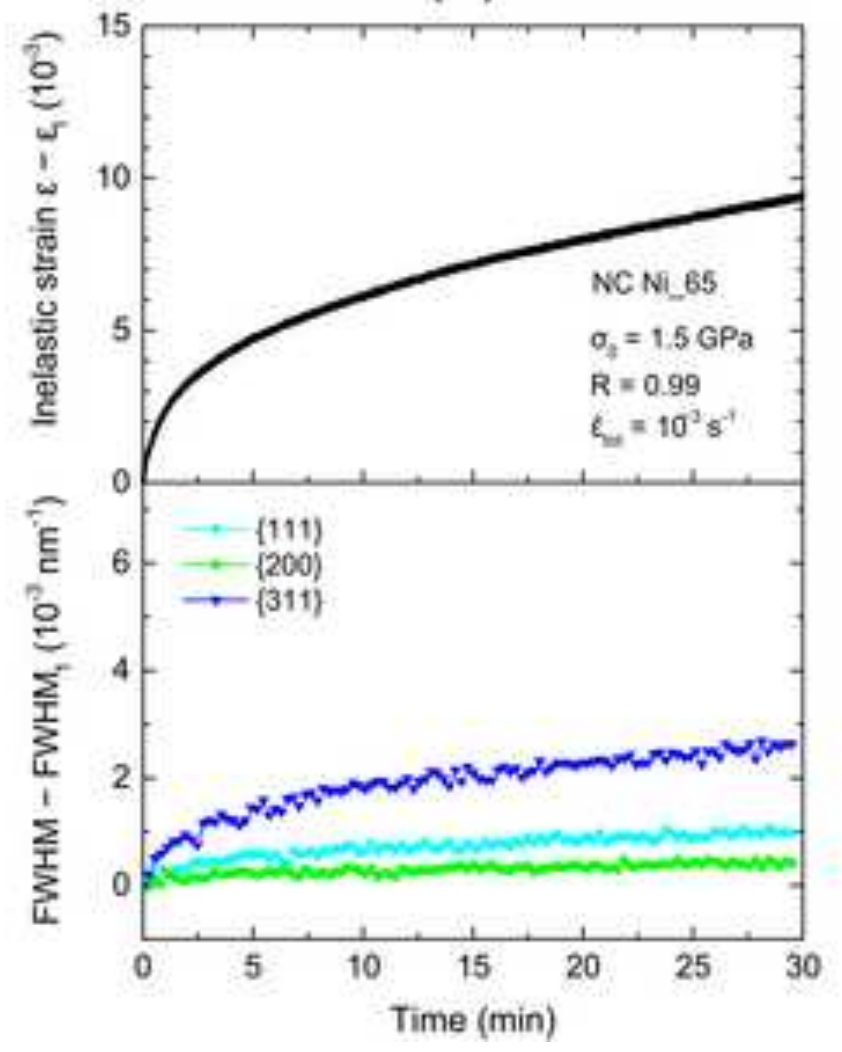

(c)

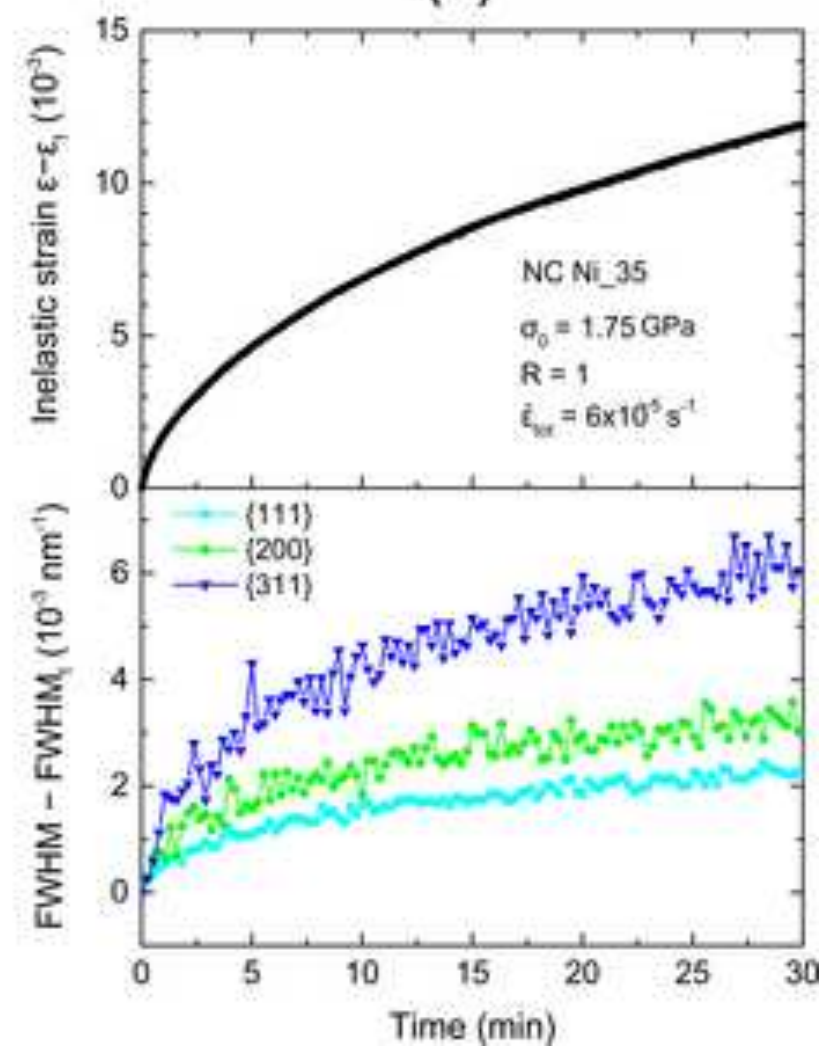


(a)

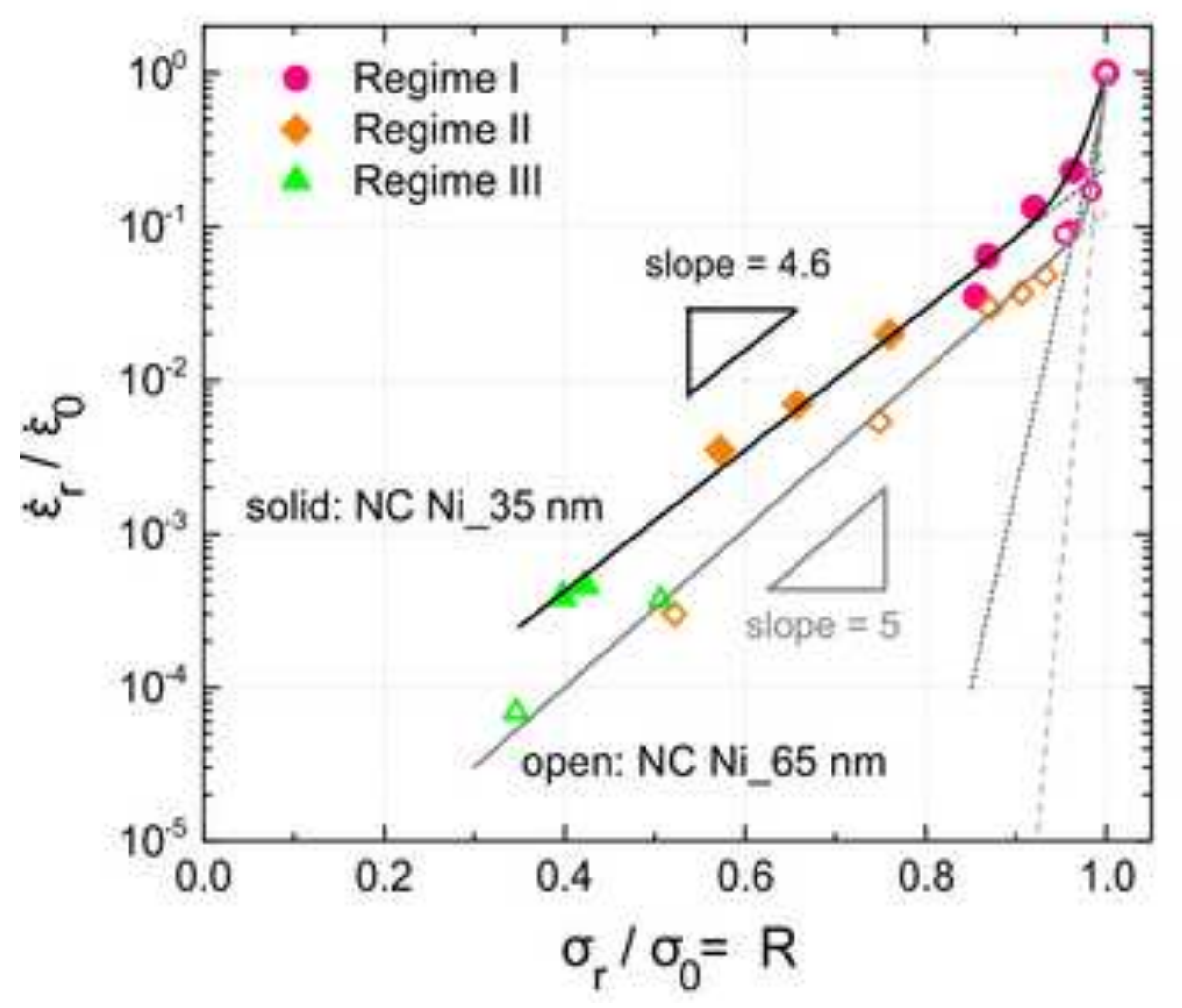

(b)

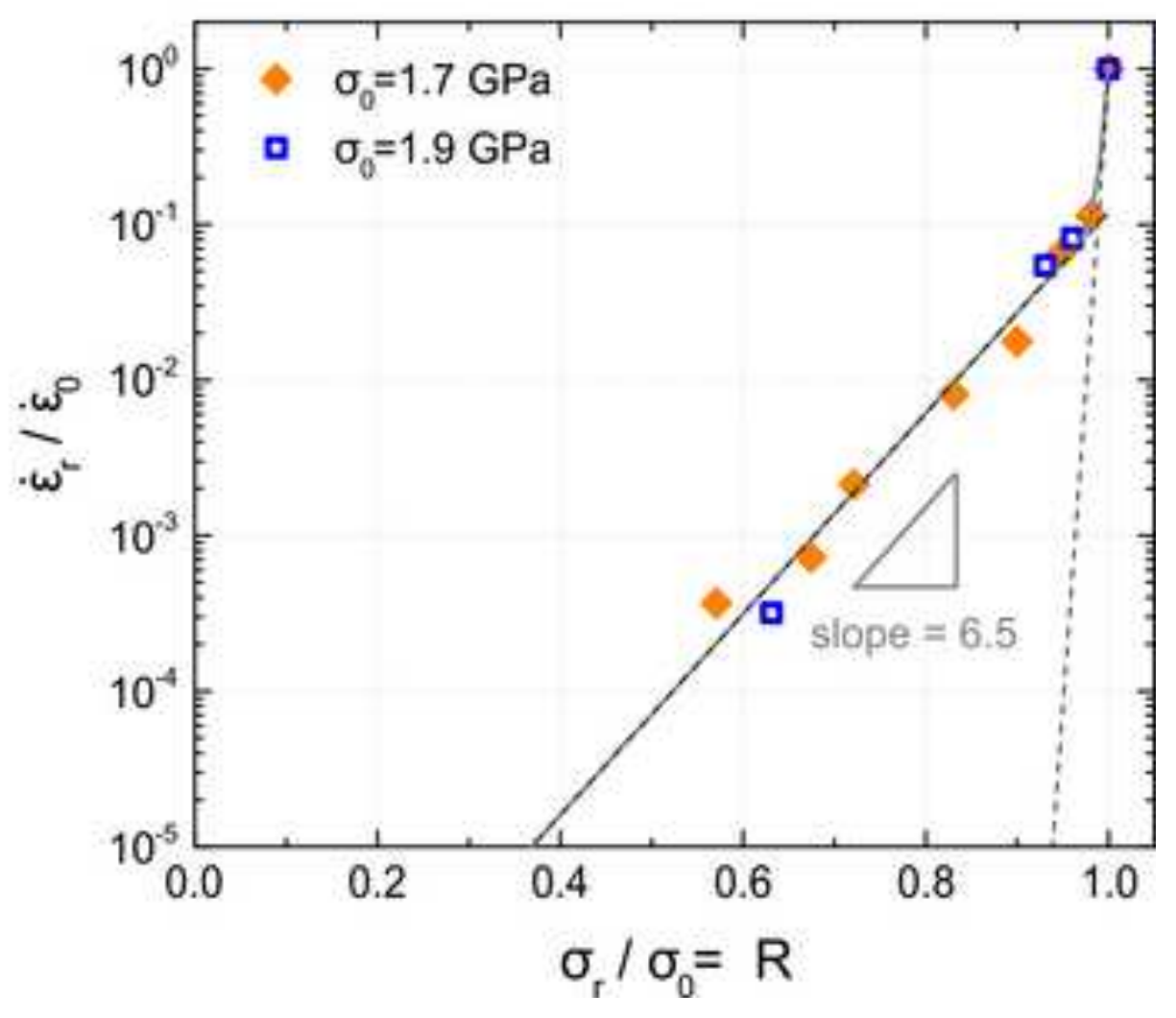




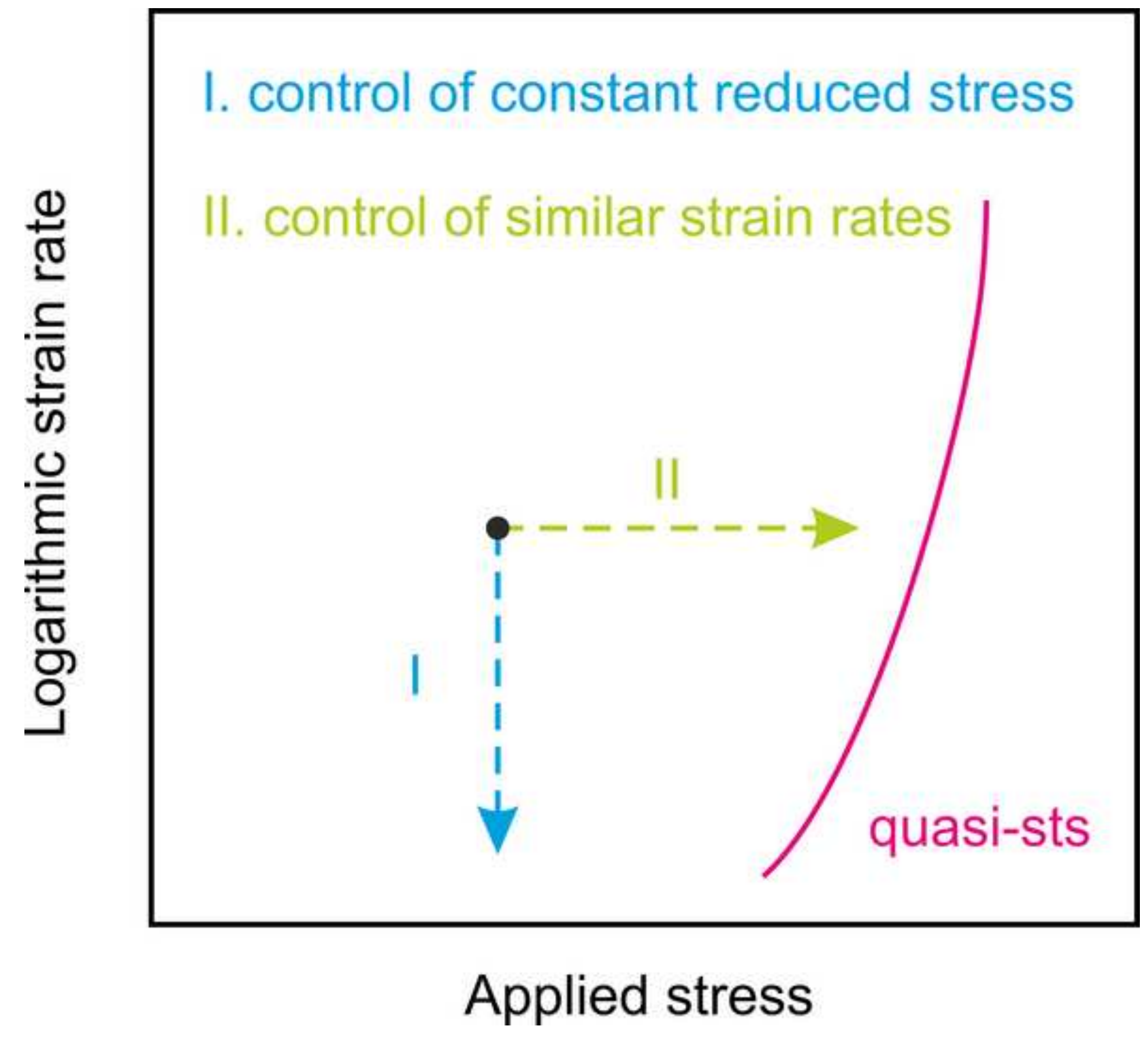




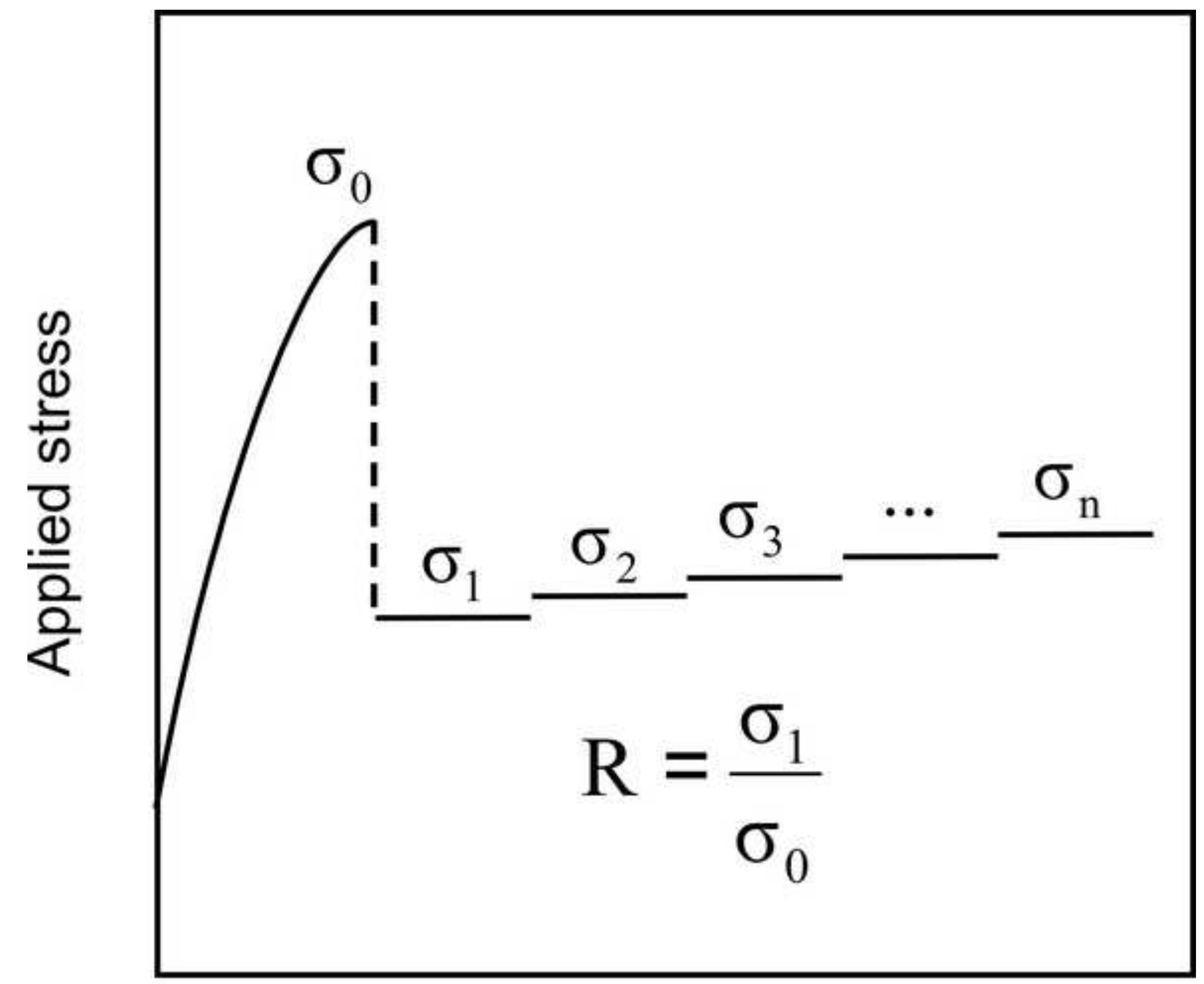

Time 

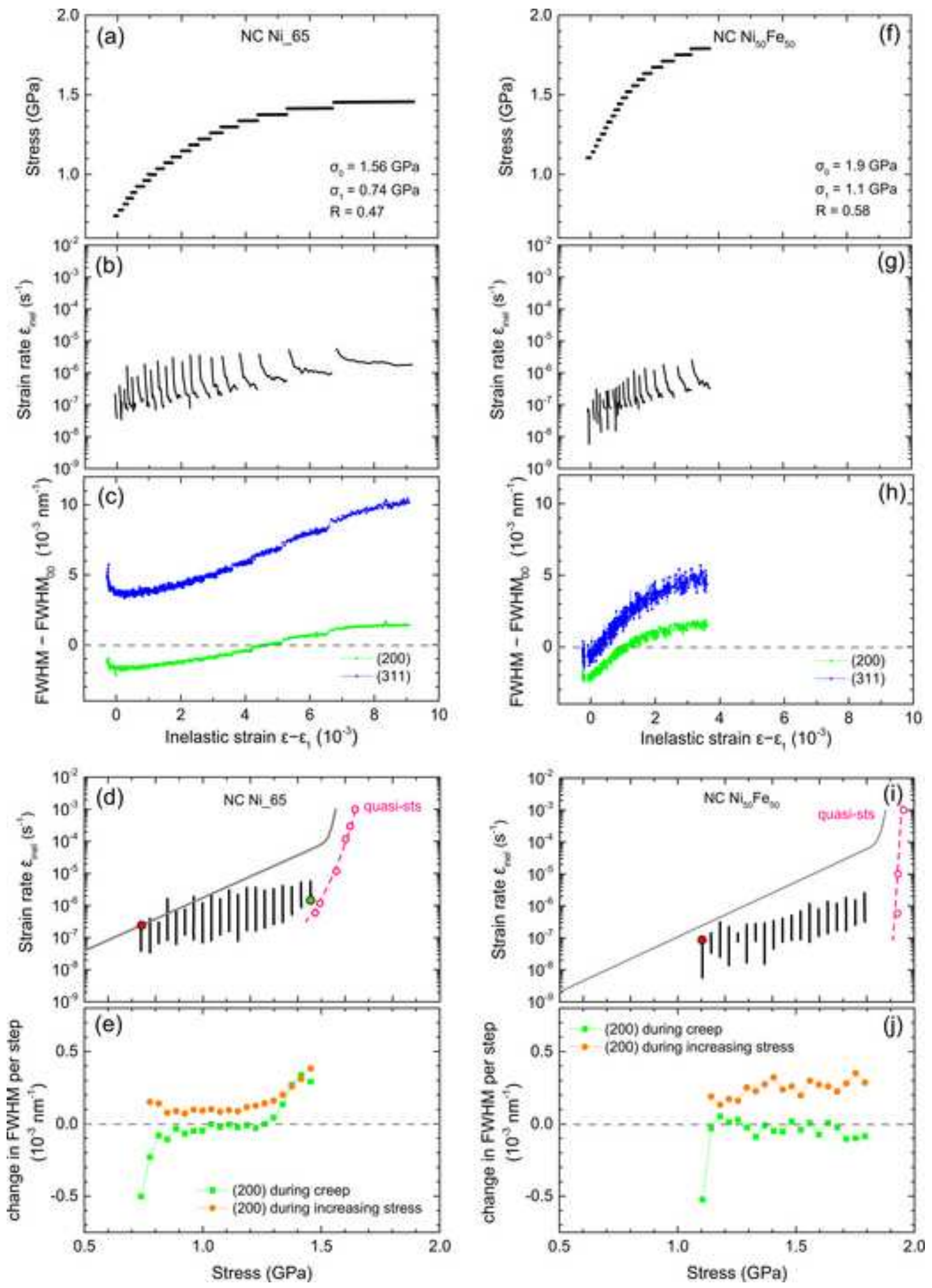


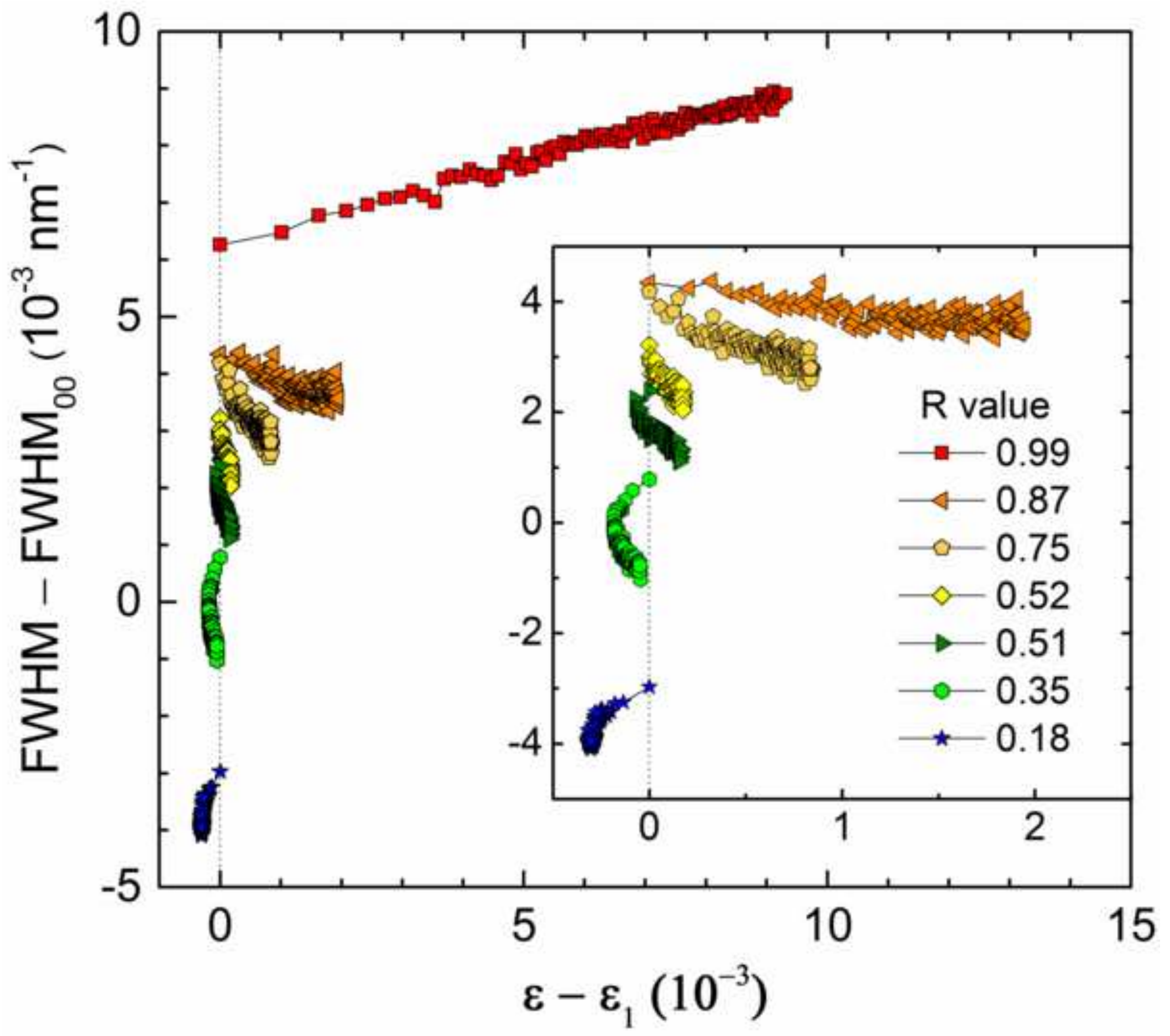




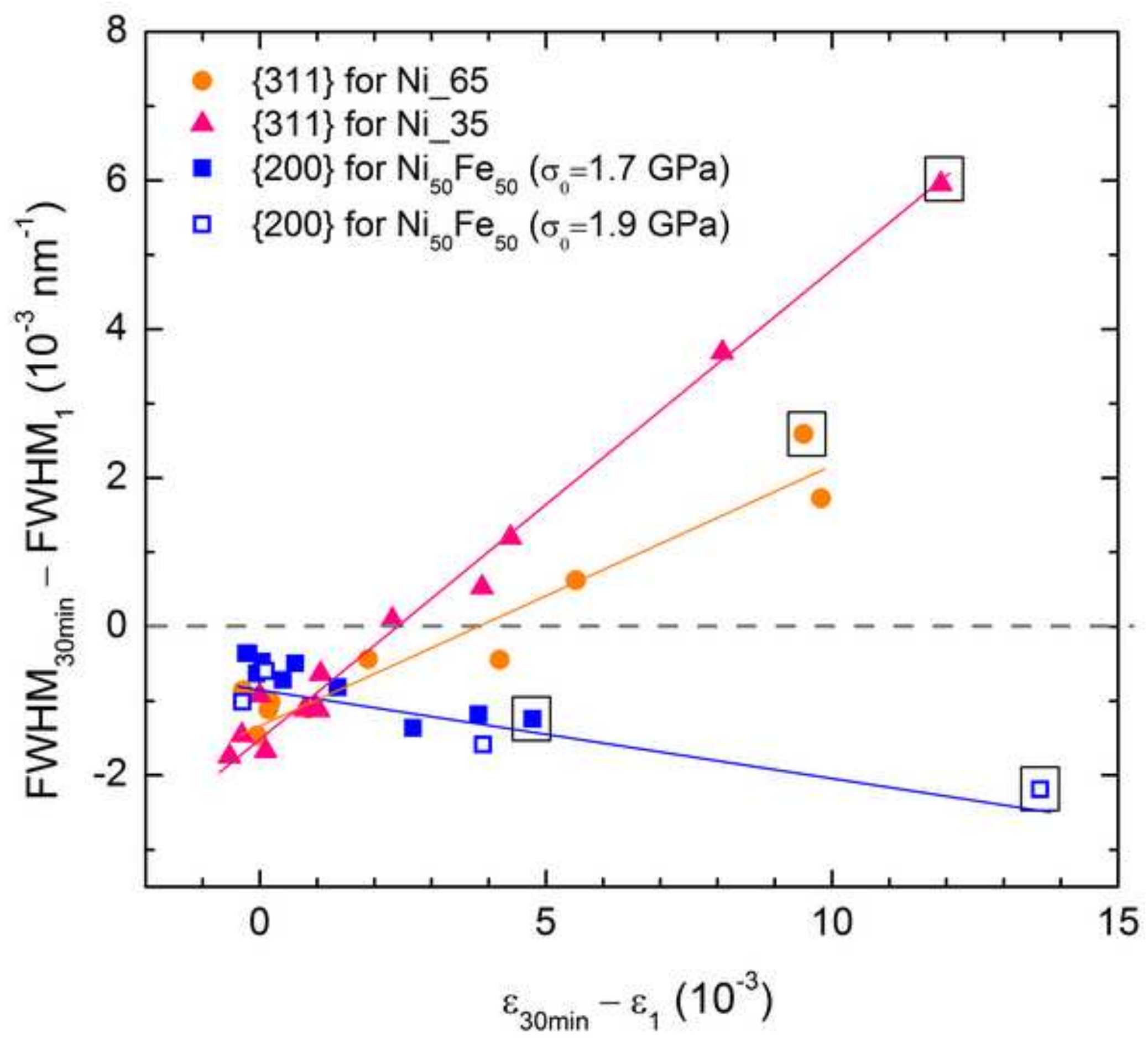




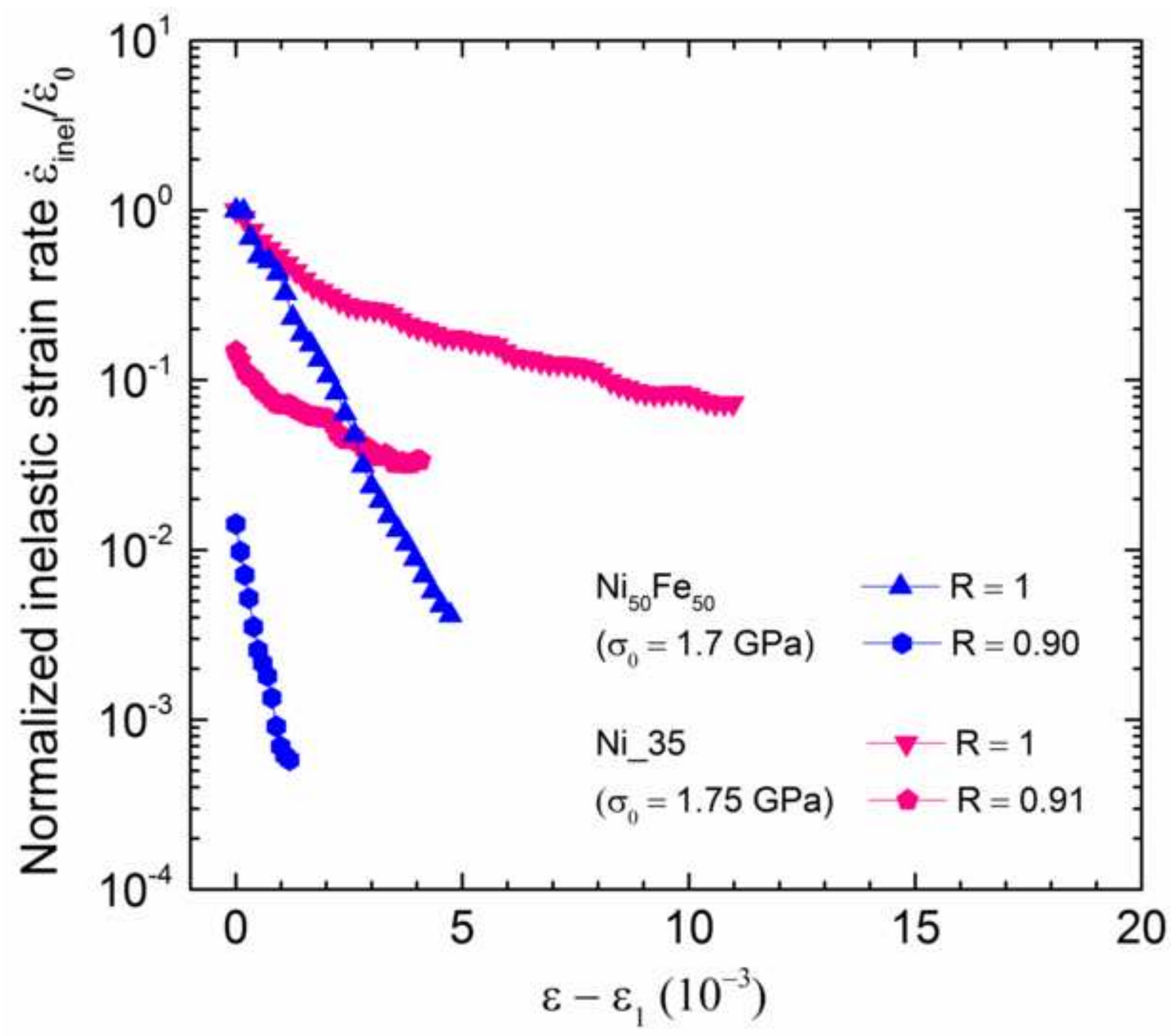




\section{List of tables}

Table 1: Deposition parameters of NC Ni

\begin{tabular}{lllllll}
\hline Pulse & Pulse & Duty & Bath & Electrolyte & Surfactant & Saccharin \\
current & repletion & cycle & temp. & {$[\mathrm{g} / \mathrm{l}]$} & {$[\mathrm{g} / \mathrm{l}]$} & {$[\mathrm{g} / \mathrm{l}]$} \\
density & rate & {$[\%]$} & {$\left[{ }^{\circ} \mathrm{C}\right]$} & & & \\
{$\left[\mathrm{mA} \mathrm{cm}^{-2}\right]$} & {$[\mathrm{Hz}]$} & & & & & \\
\hline 40 & 20 & 50 & 50 & Nickel sulfate: 280 & Sodium dodecyl & $0.5 / 1.5$ \\
& & & & Nickel chloride: 60 & sulphate: 0.2 & \\
& & & & Boric acid: 30 & & \\
\hline
\end{tabular}

Table 2: Microstructural information of the NC metals used in the present work

\begin{tabular}{llll}
\hline Material & Ratio of diffraction intensities & Average grain size & RMS strain \\
& $\mathrm{I}\{111\} / \mathrm{I}\{200\}$ & {$[\mathrm{nm}]$} & {$[\%]$} \\
\hline $\mathrm{NC} \mathrm{Ni} 35$ & 1.05 & 35 & 0.32 \\
$\mathrm{NC} \mathrm{Ni} 65$ & 0.35 & 65 & 0.29 \\
$\mathrm{NC} \mathrm{Ni}_{50} \mathrm{Fe}_{50}$ & 0.85 & 15 & 0.50 \\
\hline
\end{tabular}




\section{in situ $\mathrm{x}$-ray diffraction}

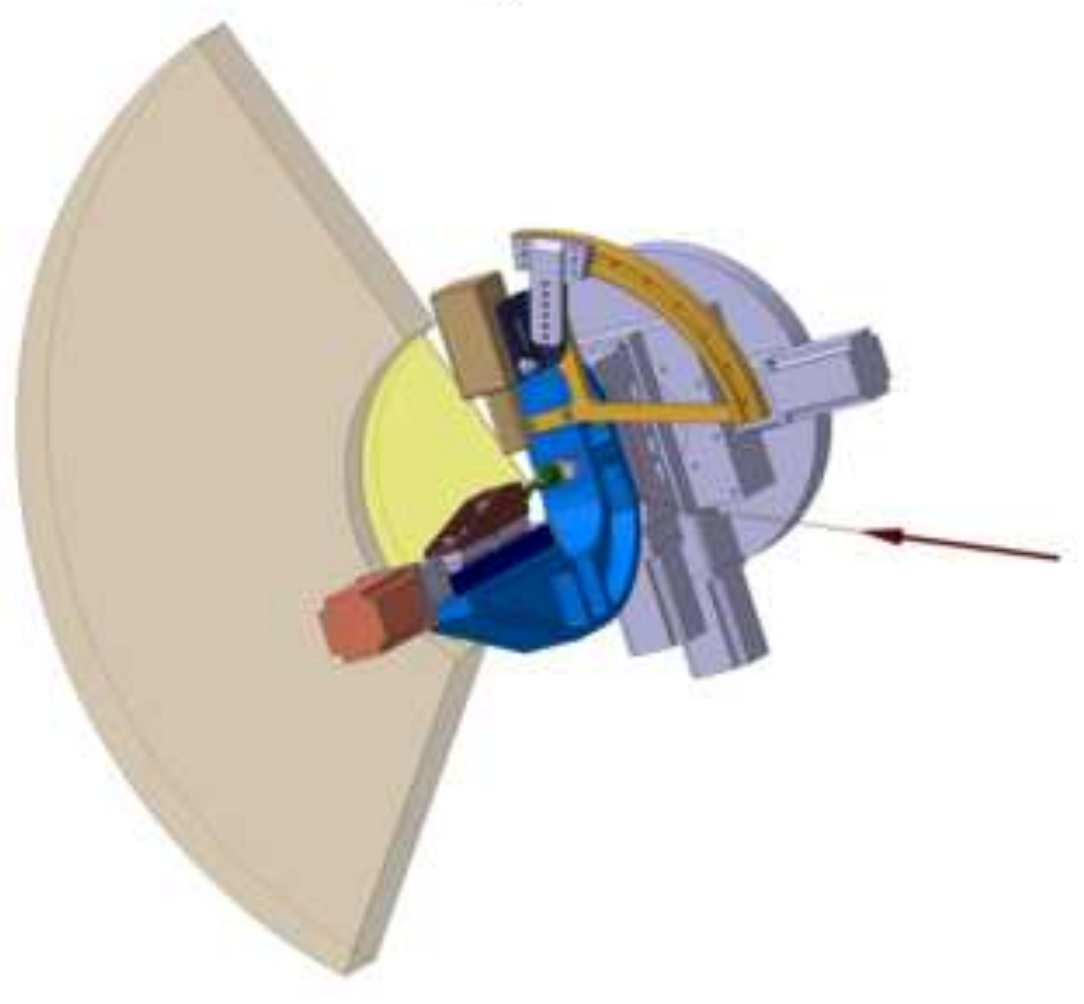

\section{stress reduction tests}

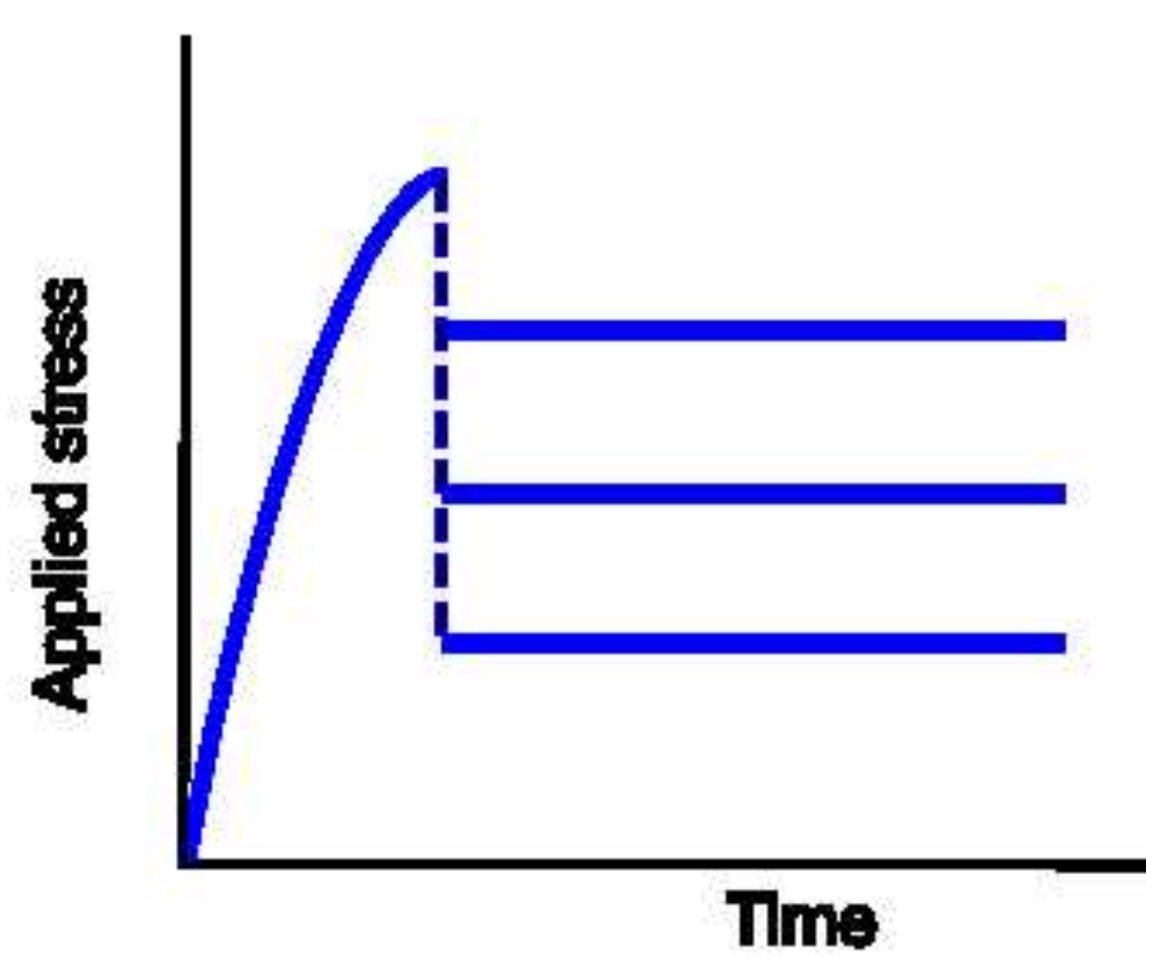

